\title{
أبعاد التفاعل الأسري في ظل جائحة كورونا المستجد (كوفيد-19) في مدينة جدة كلئة (دراسة ميدانية)
}

د. مسلم عبدالقادر مضوي أستاذ مشثارك

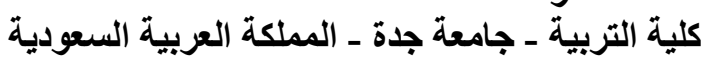
البريد الاككتروني: muslimabd777@gmail.com

الملخص

هدف البحث بصورة أساسية إلى التعرف على أبعاد التفاعل الأسري في ظل جائحة كورونا المستجد ( كوفيد 19 ) في مدينة جدة ، في أبعاده الاجتماعية و الصحية و الاقتصادية و الثخصية التي نتجت عن فرض التباعد الاجتماعي والاجراءات الصحية التي أصدرنها السطات الصحية بوزارة الصحة ، واستخدم البحث المنهج الوصفي ، وتمثل مجتمع البحث في الأسر التي تسكن مدينة جدة ، وبها خمسة أفر اد بما فيهم الزوج و الزوجة ، ، ، و استخدمت الاستبانة أداة لجمع البيانات من عينة عشوائية أُختيرت بطريقة قصدية الأنية ، وبلغ عددها مائة وخمسون أسرة قسمت إلى قسمين منساويين ، بو اقع خمس وسبعون أسرة يعمل الزوج فيها في القطاع العام ، وخمس وسبعون أسرة يعمل الزوج فيها في القطاع الخاص ، و استخدم برنامج الحزم الاحصائية في العلوم الاجتماعية في المعالجات الاحصائية ، وتوصل البحث إلى نتائج أهمها ، لجائحة كورونا آثار إيجابية على أبعاد

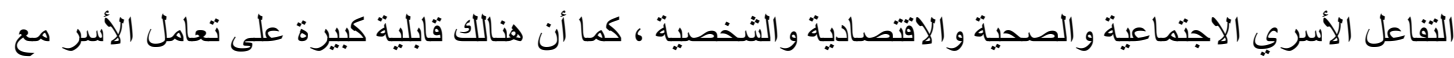
مع الطو ارئ الصحية و الأوبئة و الجوائح ، وكذلك حصول استجابة فورية وفاعلة من قبل وزارة الصحة و الجهات

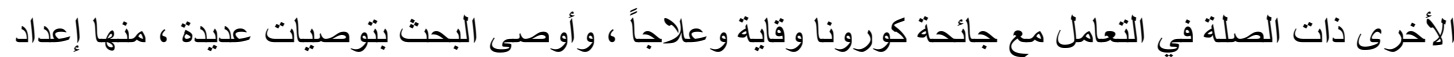
بر امج نو عية أسرية لتزويد الأسر بخبر ات تفاعلية للتعامل مع الظروف الصحية الطارئة ــ وتدريب أولياء الأمور على ممارسة مهار ات التفاعل الأسري الإيجابي . عزئ. 


\title{
$=-$ \\ Dimensions of Family Interaction in light of the Corona Pandemic (Covid- 19) in Jeddah (A field study)
}

\author{
Dr.Muslim A. Mudawi \\ Associated Professor \\ College of Education - University of Jeddah - Kingdom of Saudi Arabia \\ Email: muslimabd777@gmail.com
}

\begin{abstract}
The research aimed mainly to identify the dimensions of family interaction in light of the Corona pandemic 2019 AD in Jeddah, in its social, health, economic and personal dimensions that resulted from imposing social distancing and health measures issued by the health authorities in the Ministry of Health, the research used the descriptive methodology, and it represents the research community in families. The questionnaire was used to collect data from a random sample, the questionnaire amounted to one hundred fifty families divided into two equal parts, with seventy-five families in which the husband works in the public sector, and seventy-five families the husband works in it in the private sector, and used the Statistical Package in Social Sciences (SPSS) program in statistical treatments, the research results, the most important of which are that the Corona pandemic has positive effects on the social, health, economic and personal dimensions of family interaction, and there is a great capacity for families to deal with health emergencies, epidemics and pandemics, as well as an immediate and effective response from the Ministry of Health and other relevant bodies the relationship in dealing with the Corona pandemic, prevention and treatment, the research recommended many recommendations, including the preparation of family awareness programs to provide families with interactive experiences to deal with emergency health conditions, and also training parents to practice positive family interaction skills.
\end{abstract}

Keywords: family interaction, social interaction, the new Corona Covid-19. 


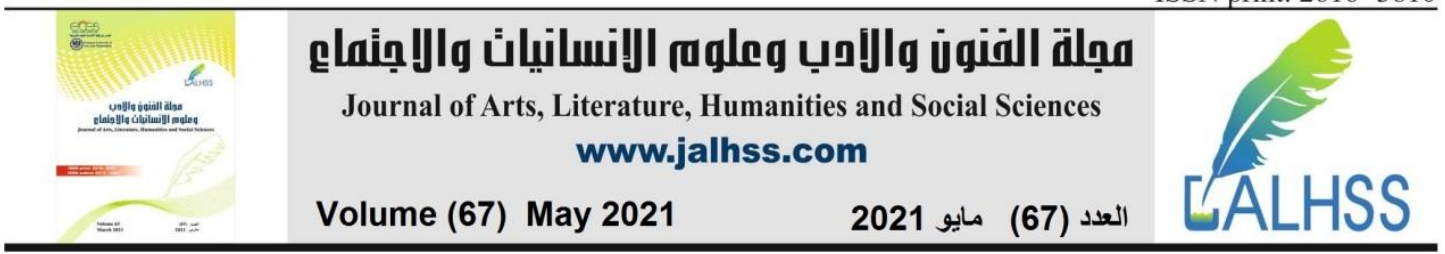

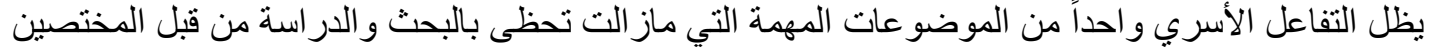

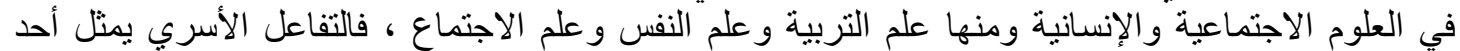

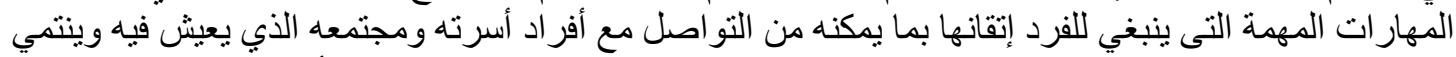

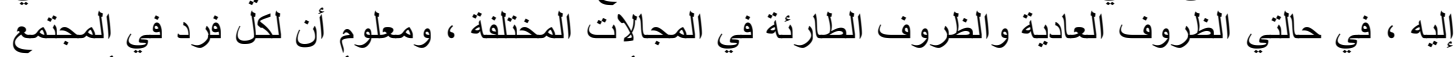

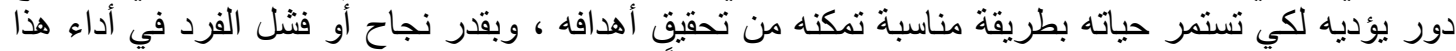

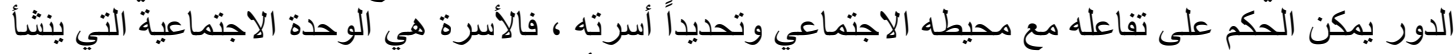

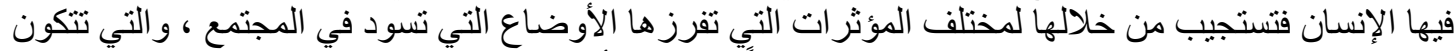

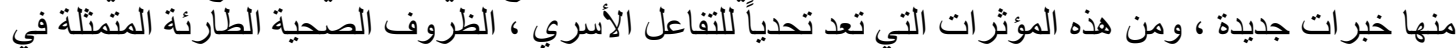

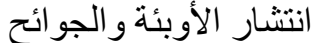

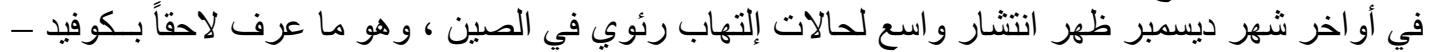
19 (Corona virus disease -19 ) ومن ثم بدأت العديد من دول العالم في التأهب و والإستجابة بطرق الإنة

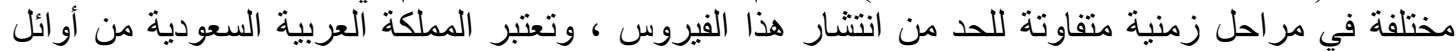

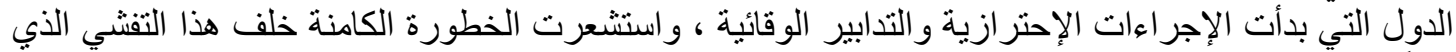

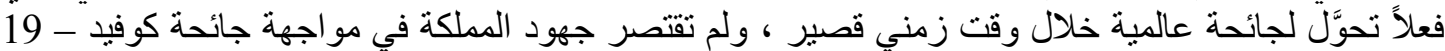

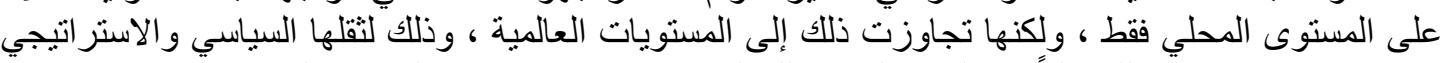

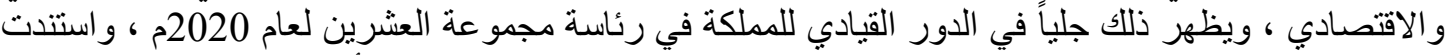

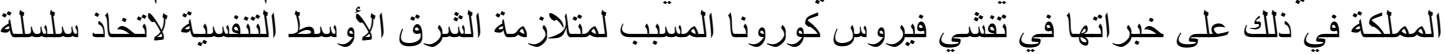

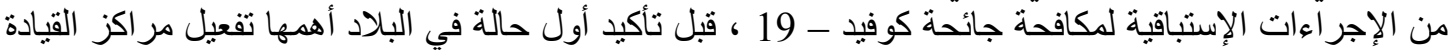
و التحكم ، وتعليق السفر إلى الصين ، وتعليق دخول المملكة بالفيزا السياحية ـ وثيقة تجربة الإلية المملكة العربية

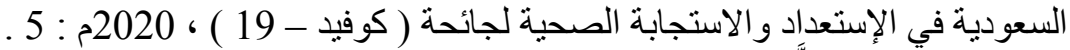

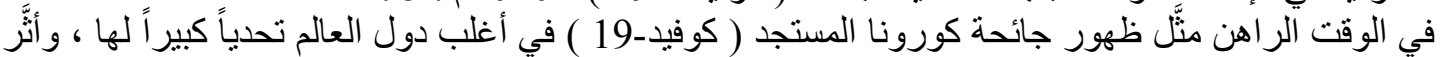

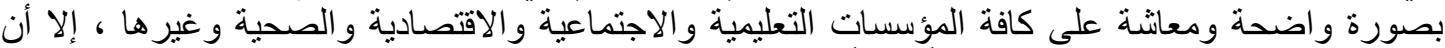

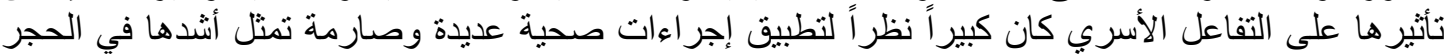

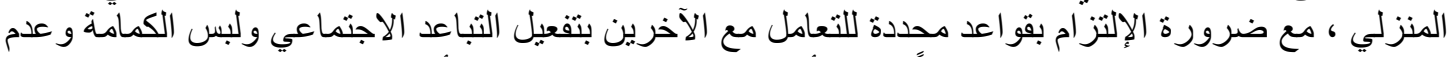

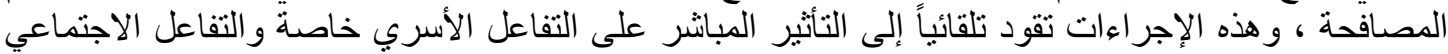

عامة. . ع

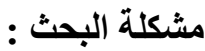

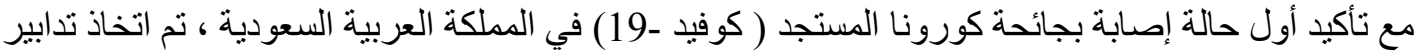

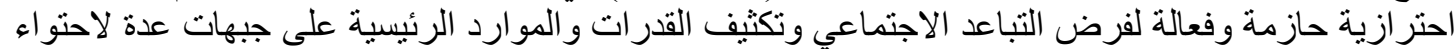

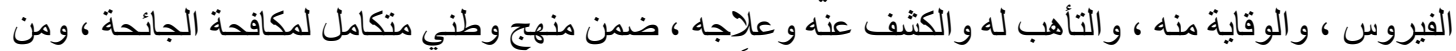

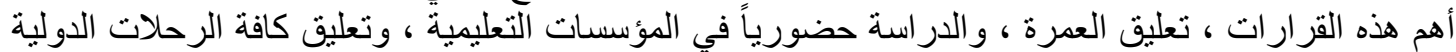

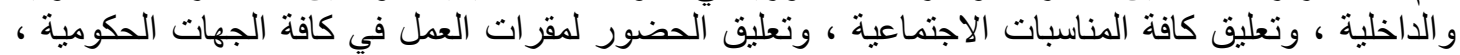

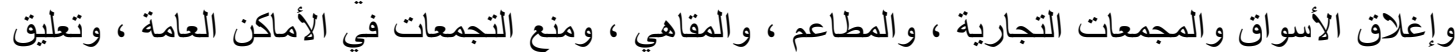

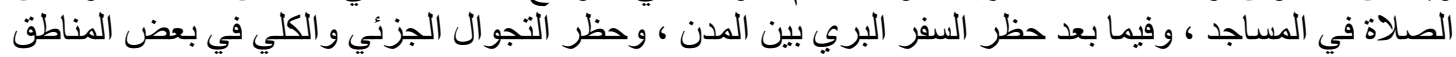

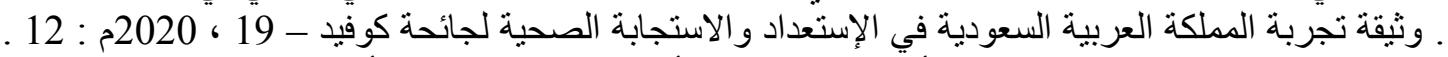

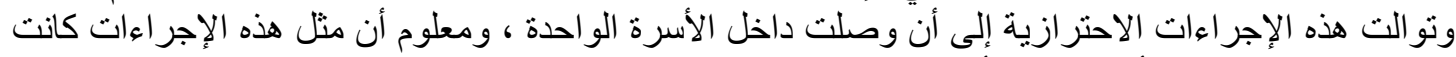

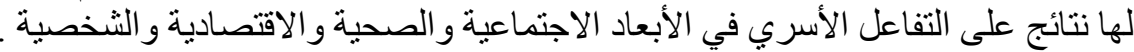

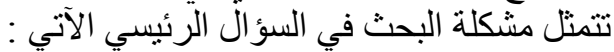

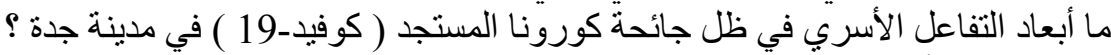

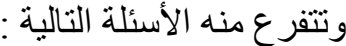

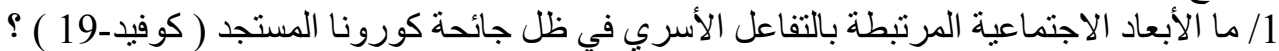
2/ ما الأبعاد الصحية المرتبطة بالتفاعل الأسري في ظل جائحة كورونا المستجد ( كوفيد-19 ) ؟ 


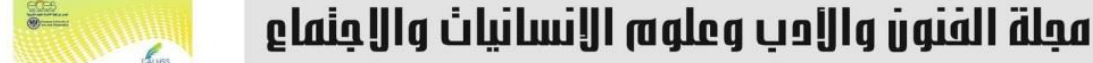 \\ Journal of Arts, Literature, Humanities and Social Sciences www.jalhss.com \\ Volume (67) May 2021 \\ العدد (67) م مايو 2021 \\ ¿ÁLHSS}

3/ ما الأبعاد الاقتصادية المرتبطة بالتفاعل الأسري في ظل جائحة كورونا المستجد ( كوفيد-19 ) ؟

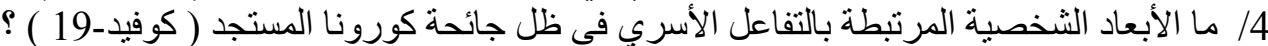

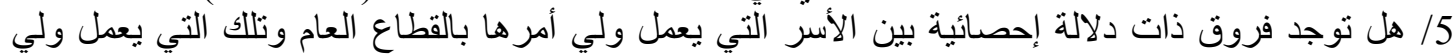

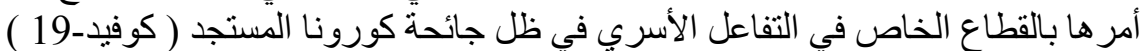

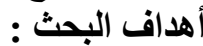

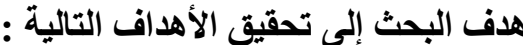

1/ التعرف على أبعاد التفاعل الأسري الاجتماعية و الاقتصادية والصحية و الثخصية في ظل جائحة كورونا

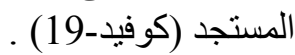
2/ التعرف على العلاقة الإرتباطية بين أبعاد التفاعل الأسري الاجتماعية والاقتصادية و الصحية والشخصية

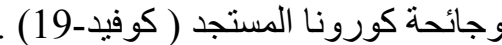
3/ تقديم توصيات للجهات المسؤولة قد تفيد في وقف انتشار هذه الجائحة ، و التعامل مع ما يمانلها من طوارئ

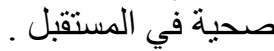

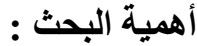
الأهمية النظرية : النجية

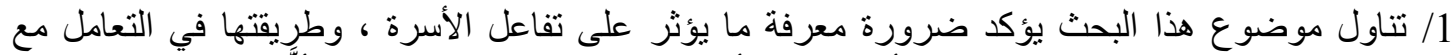

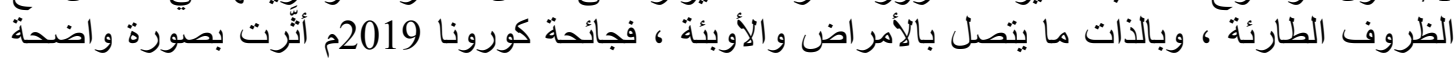

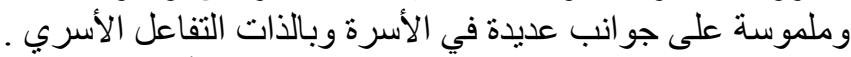

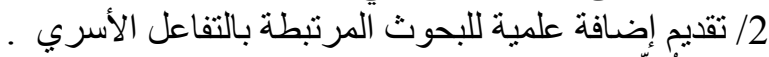

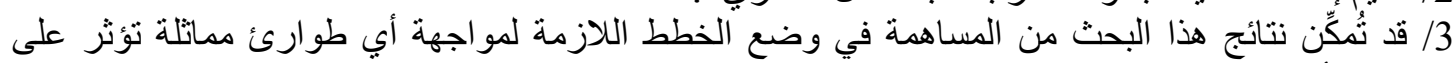
التفاعل الأسري. 4/ إثر اء البحوث و الدر اسات في مجالات التفاعل الأسري ، وبالذات ما يتصل منها بحدوث الأوبئة و الجوائح .

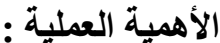
1/ قد تلقي نتائج هذا البحث الضوء على على أهم المنطلبات التي يجب توفيرها للأسرة حين ظهور الجوائح والأوبئة . 2/ قد يفيد هذا البحث في تهيئة العاملين في المهن الصحية في التهيؤ و الإستعداد المستمر للتعامل مع الطوارئ التئ 3/ يتوقع أن تساعد نوصيات هذا البحث في اقتر اح وتقديم توصيات في إقامة شر اكات مع جهات رسمية أخرى

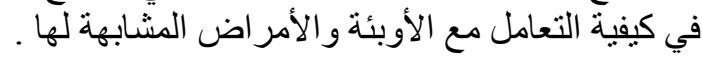
4/ مساعدة المسؤولين في وزارة الصحة في الإستجابة الصنة للطو ارئ الصحية . يستخدم هذا البحث المنهج الوصفي لمناسبته لطبيعة البحث ، و هو يستخدم لوصف الظواهر القائمة لمعرقة خصائصها ، كما يصف العلاقات المنداخلة بينها لمحاولة استقر اء ما يرتبط بها في المستقبل ـ مطاوع و الخليفة . 33 : 2017

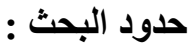
• حدود موضو عية : أبعاد التفاعل الأسري في ظل جائحة كورونا المستجد .

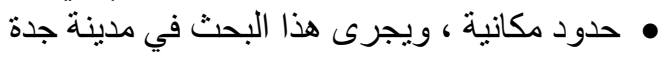

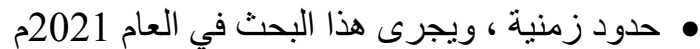
• حدود بشرية ، وتشمل الأسر التي بها ثلاثة أطفال فأكثر إضافة إلى الزوجين .

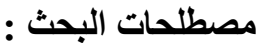
1/ أبعاد ، جمع بُعد ، أبعاد الموضوع ، أبعات العماقه وما يتعلق به . عمر ، 1989م : 1/ 354 ـ أما اصطلاحاً فيقد

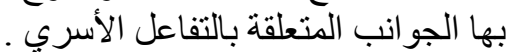
2/ التفاعل الأسري ، هو مستوى وطُبيعة العلاقات الاجتماعية السائدة بين أفر اد الأسرة الواحدة و الذي يتم بطرق

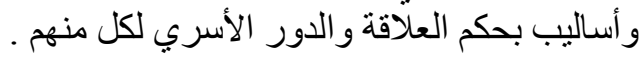




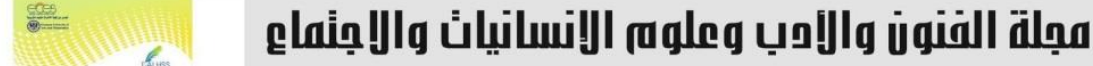 \\ Journal of Arts, Literature, Humanities and Social Sciences www.jalhss.com \\ Volume (67) May 2021

العدد (67) م مايو 2021 \\ AALHSS}

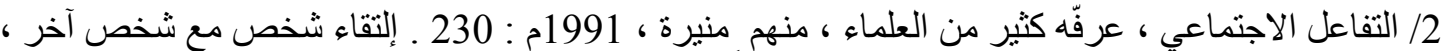

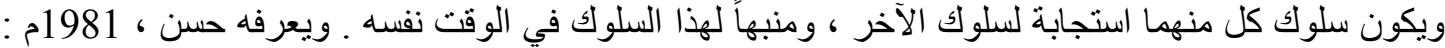

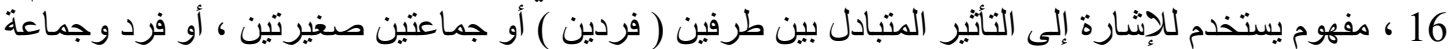
صغيرة أو كبيرة ، يؤثر كل منهما في سلوك الآخر ، ويتبنى الباحث هذا التعريف للتفاعل الاجتماعي لمناسبته

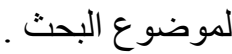

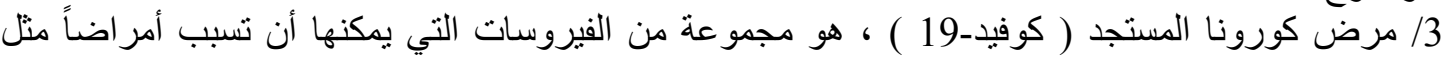

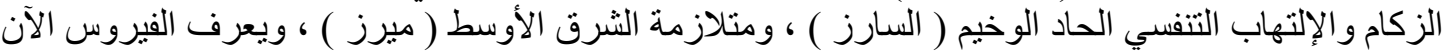

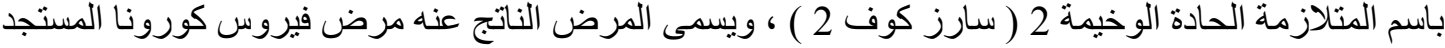

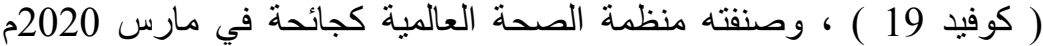
https://www.mayoclinic.org 19/01/2021

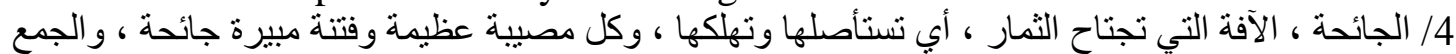

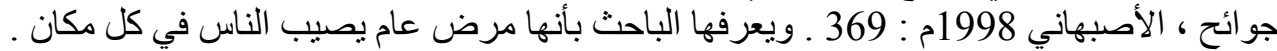

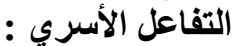

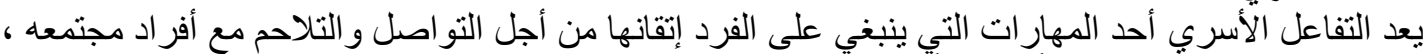

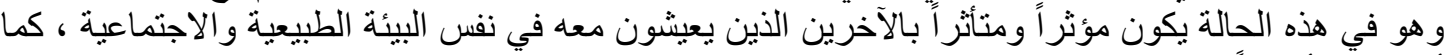

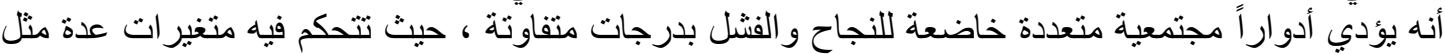

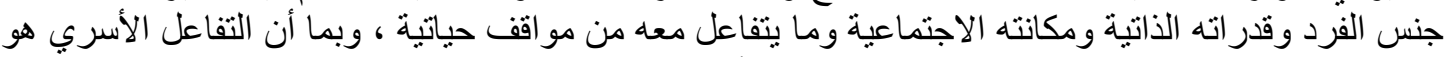

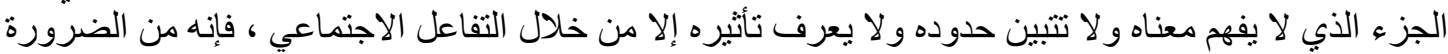

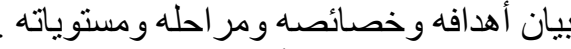
للتفاعل الاجتماعي أهداف عديدة ، تكون محصلتها النهائية التهائ حدوث توافق بين الفرد ومجتمعه ، ومن أهم هذه

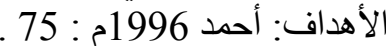

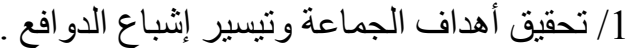

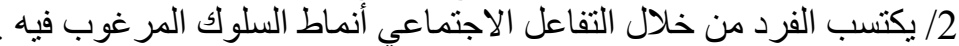

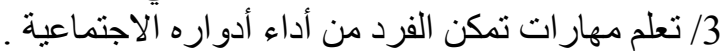

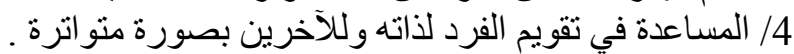

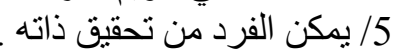
6/ بمكن من الوقاية من الأمر اض اضن النفسية .

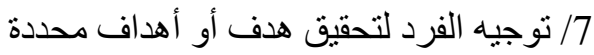

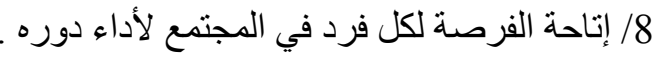

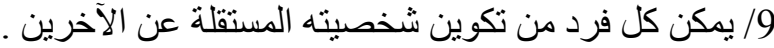

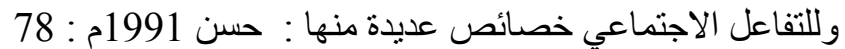

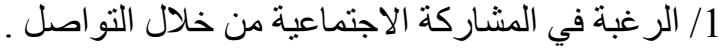

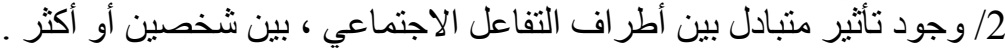

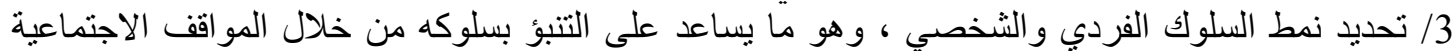

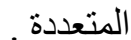

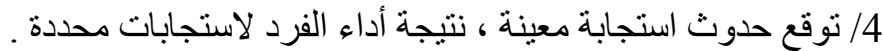

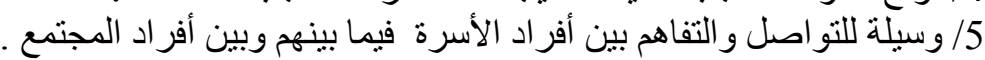

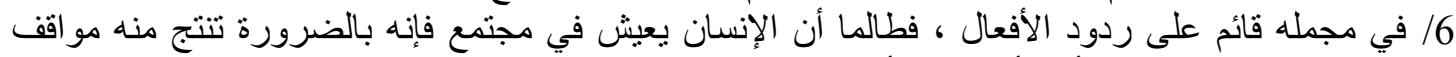

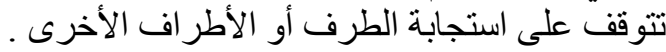

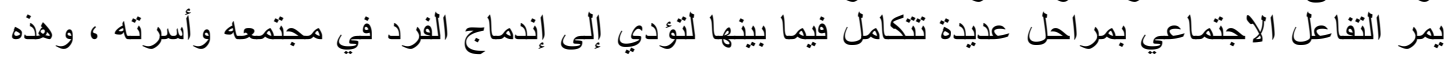

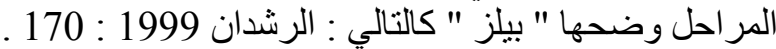
1/ التعرف : أي الوصول إلى تعريف مشترك للموقف التوف ، ويشمل ذلك طلب المعلومات والإعادة و التوضيح

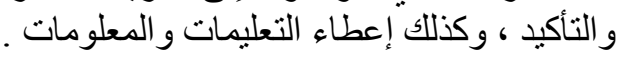




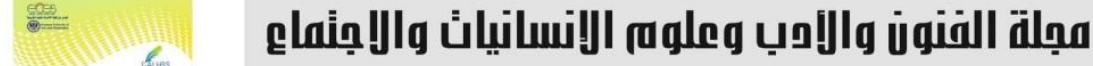 \\ Journal of Arts, Literature, Humanities and Social Sciences www.jalhss.com \\ Volume (67) May 2021 \\ العدد (67) مايو 2021 \\ ¿ÁLHSS}

2/ التقييم : أي تحديد النظام المشترك الذي تُقيَّم في ضوئه الحلول المختلفة ، ويشمل ذلك طلب الر أي و التحليل

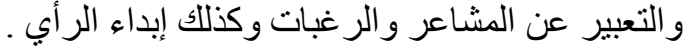
3/ الضبط : أي محاو لات الأفر اد للتأثثير في بعضئه بعضاً ، ويشمل ذللك طلب الاقتر احات و التوجيه و الطرق

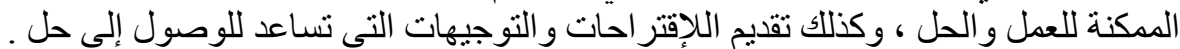

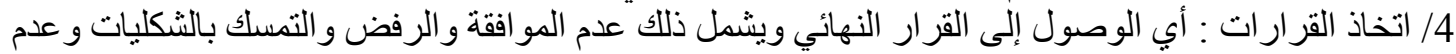

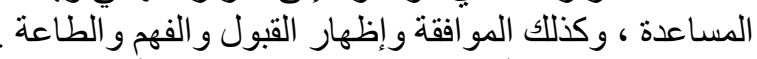

5/ ضبط التوتر : أبي علاج التوترات التي تنشأ في الجماعة ، ويشمل ذلك إظهار التوتر و الإنسحاب من ميدان

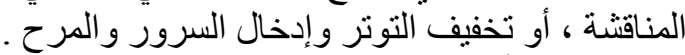

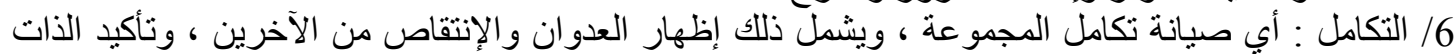

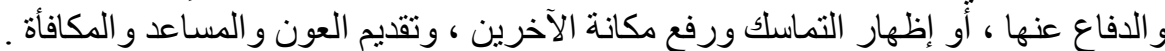

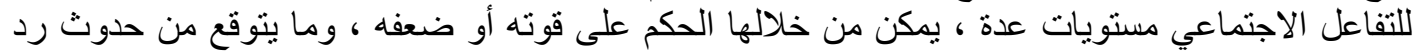

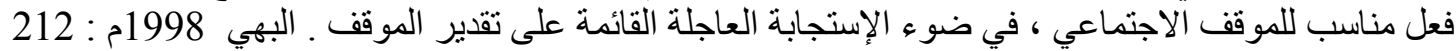
، ومن خلال هذه المستويات يتبين بوضوح أن التفاعل الأسري هو التطبيق الفعلي للعلاقات الإجتماعية السائدة المستوى المجتمع الأول : العلاقات التبادلية ، وتعني وجود فردين معاً ، ولكن لا تتكون بينهما علاقات اجتماعية ،

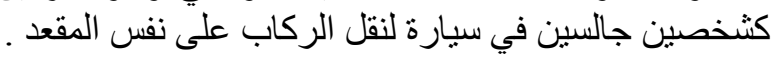

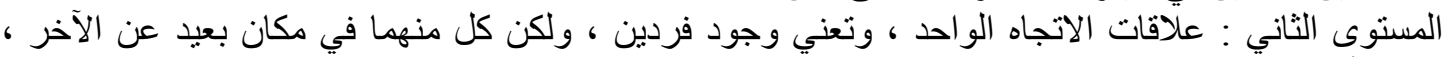

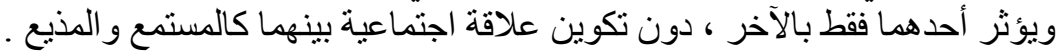

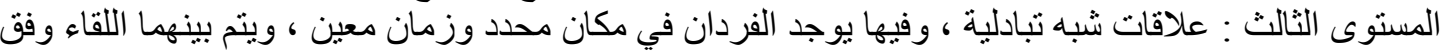

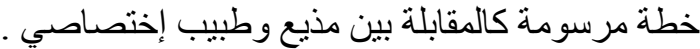
المستوى الر ابع : العلاقات المتوازية ، وفيها يتواجد فردان في مكانة مكان محدد ، وزمان معين، حيث بتحدث كل

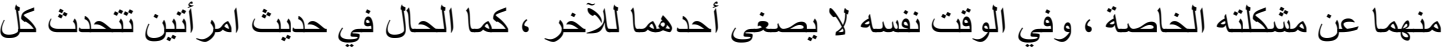

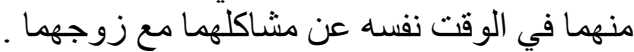
المستوى الخامس : العلاقات المتبادلة غير المتناسقة ، وفيها يوجد فردان فران في مكان محدد وزمان معين ، وتعتمد استجابات أحدهما على سلوك الآخر ، كما بحدث في مقابلة الأخصائي الاجتماعي لفرد في عينة البحث

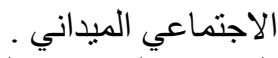
المستوى السادس : العلاقات المتبادلة ، وفيها يوجد فردان بمكان محدد وزمان معين ، وتتكون علاقات اجتماعية

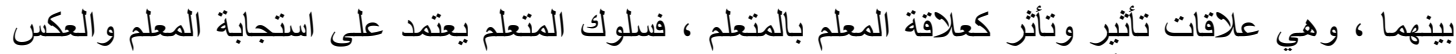
صحيح ، و هناك من يقول أنه العلاقات الاجتماعية الحقيقية التي تعكس مفهوم التفاعل الاجتماعي ـ و هذا المستوى فئم هو ما يقصده هذا البحث.

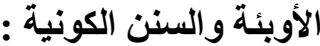

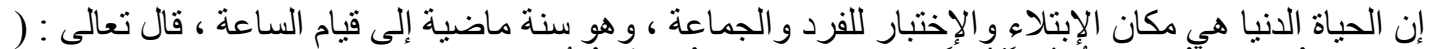

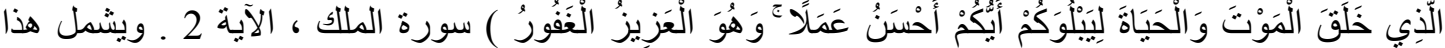

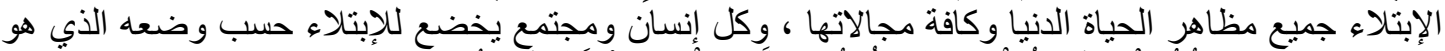

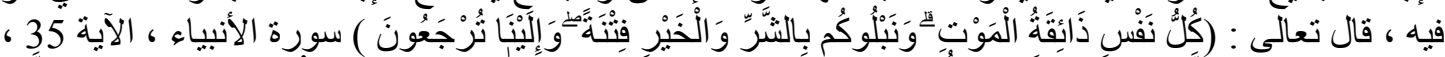

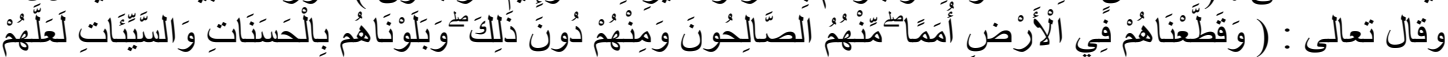

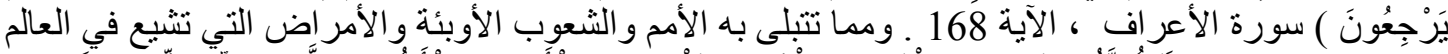

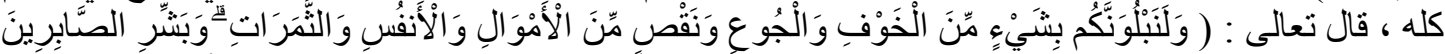

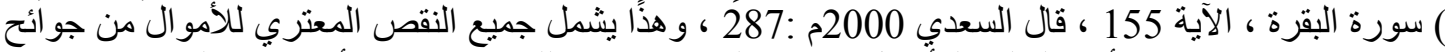

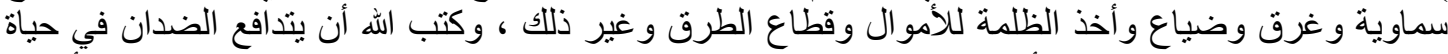

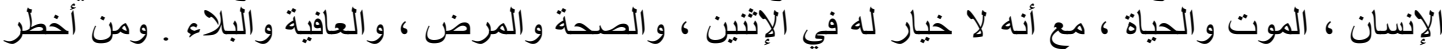

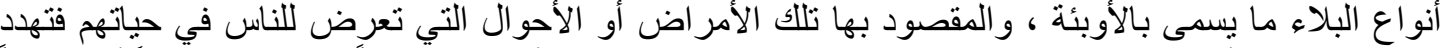

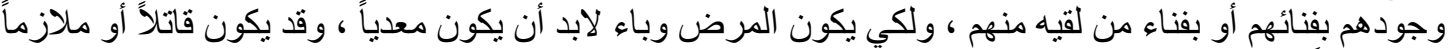

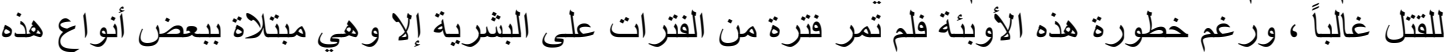




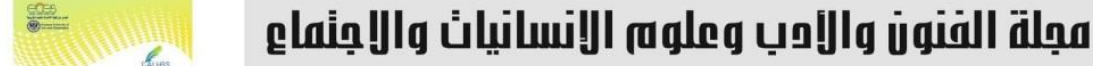 \\ Journal of Arts, Literature, Humanities and Social Sciences www.jalhss.com \\ Volume (67) May 2021 \\ العدد (67) مايو 2021

الأوبئة ـ . Salafcenter.org. 19/1/2021. ومهما فعل الإنسان للخروج من هذا الإبتلاء و الإختبار ، فإنه لا يبعد

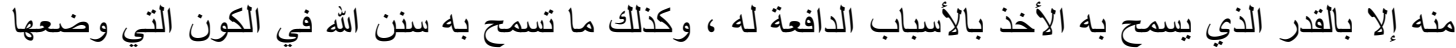

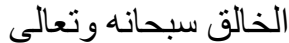
إن من مقاصد الثريعة الإسلامية حفظ النفس ، وقد بيَّن الإسلام أنه لا تهاون و لا نساهل في كل ما بلحق

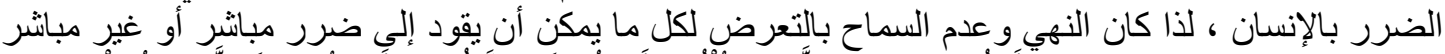

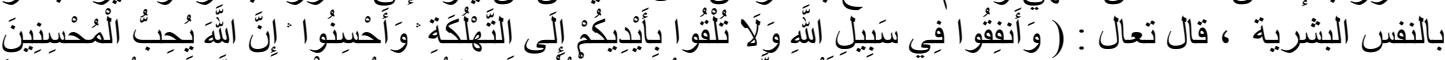

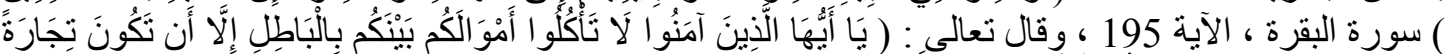

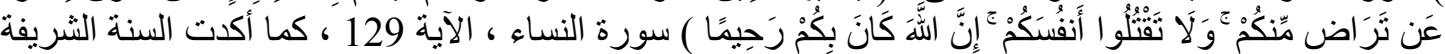

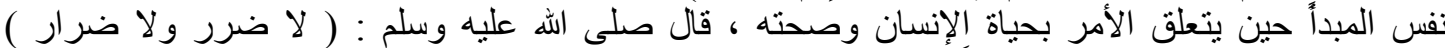

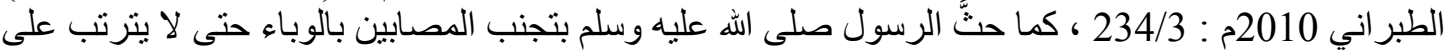

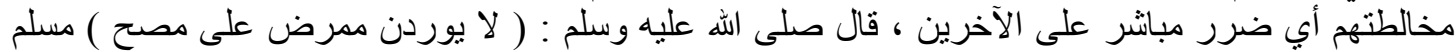

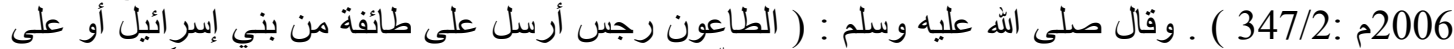

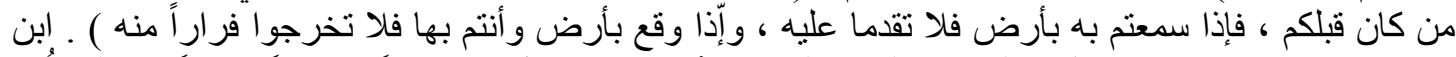

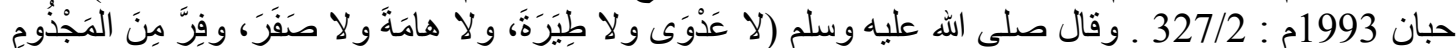

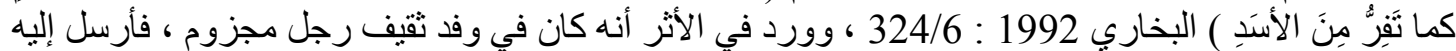

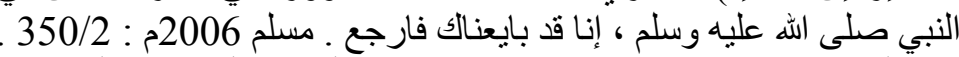

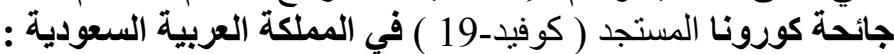

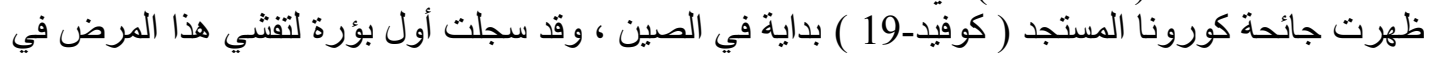

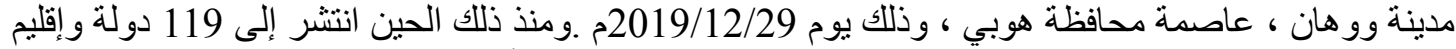

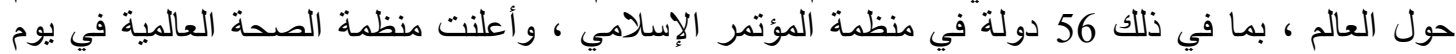

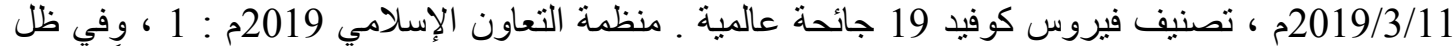

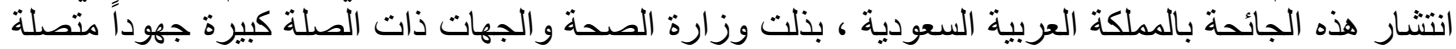

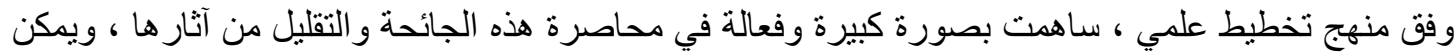
بيان بعض هذه الجهود فيما يلي : وثثيقة تجربة المملكة الكربية السعودية في الإستعداد والاستجابة الصحية الصانة

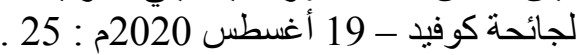

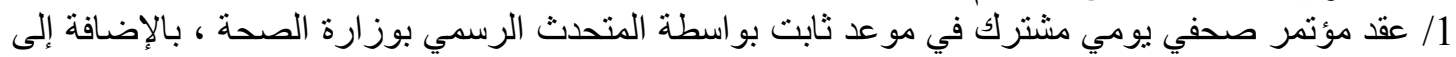

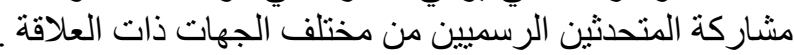
2/ إرسال أكثر من 6,6 مليار رسالة نصية توعن الرية عن عن كوفيد- 19 ، انتملت على نصائح و ارشادات للتعامل مع الفيروس ، ومنع انتشاره ه.

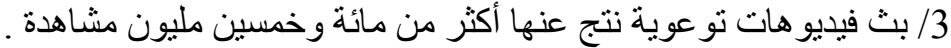

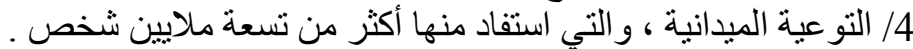

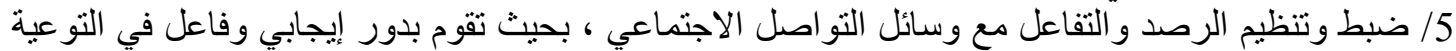

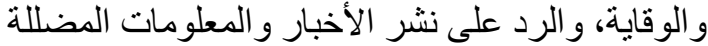

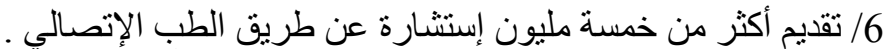

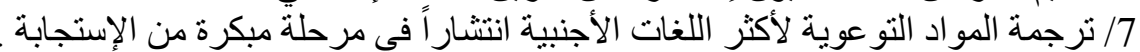

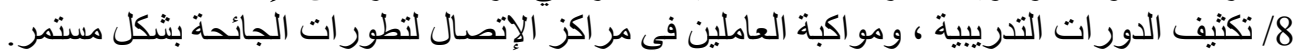

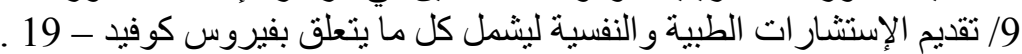

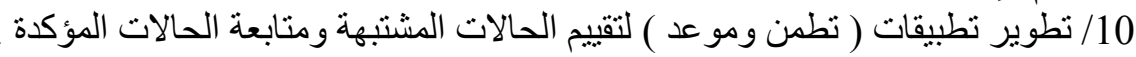

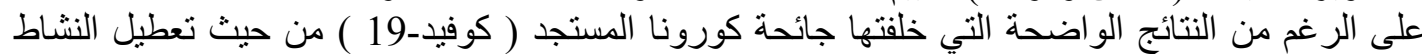

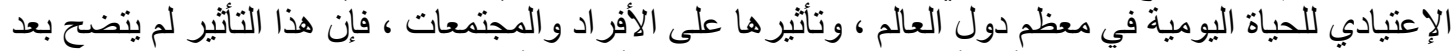

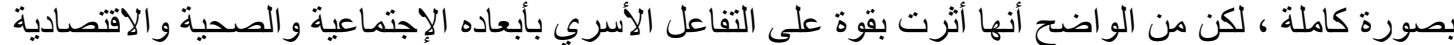
و الثخصية وغير ها ، ويمكن بيان هذه التفاعلات بشقيها الإيجابي و السلبي كالتالي : 


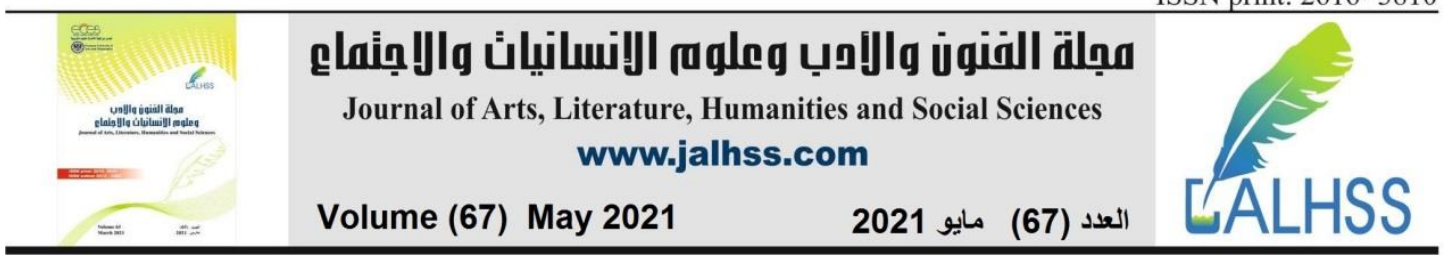

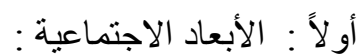

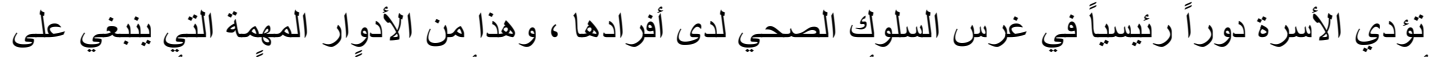

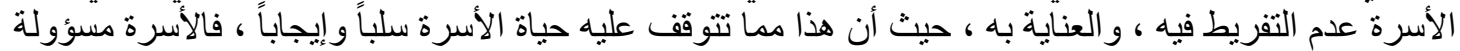

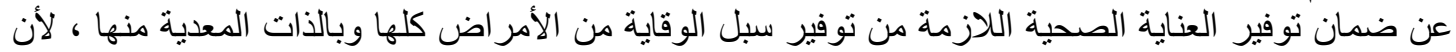

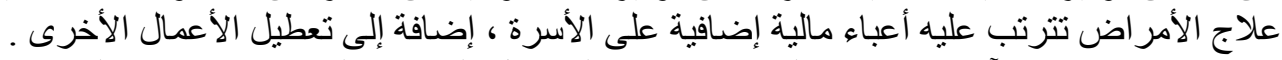

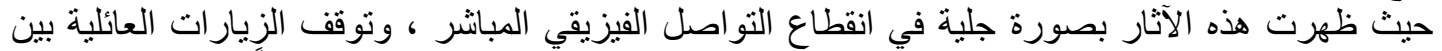

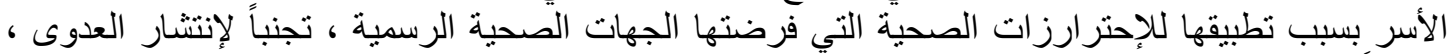

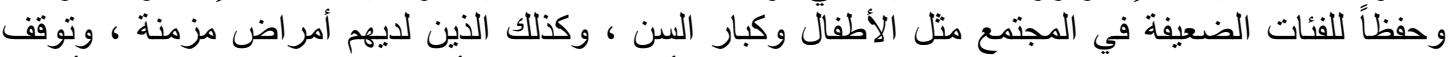

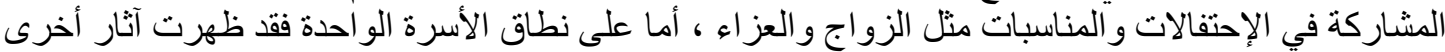

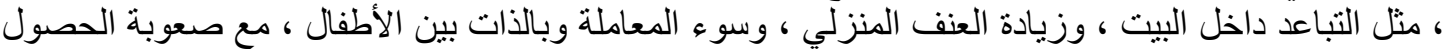

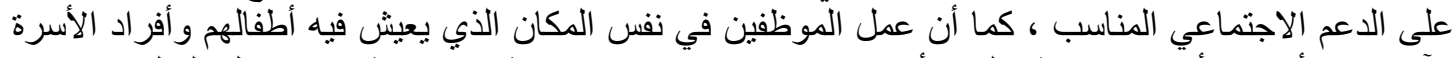

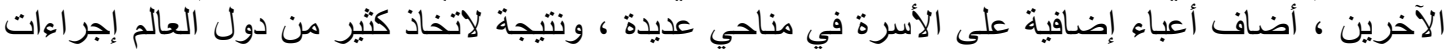

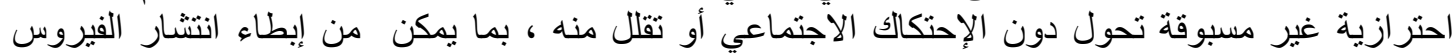

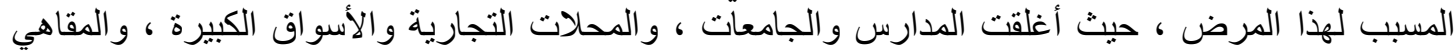

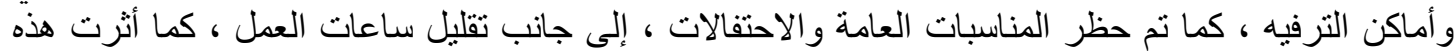

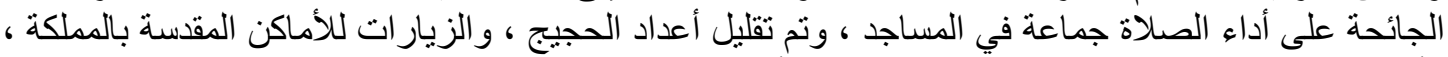

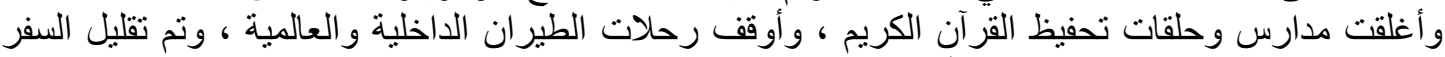
بوسائل المو اصلات المختلفة ، كذلك تأثرت قيم التقارب الإنساني عن طريق المصافحة باليد و القبلات و التواصل

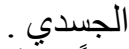

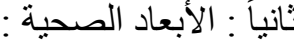

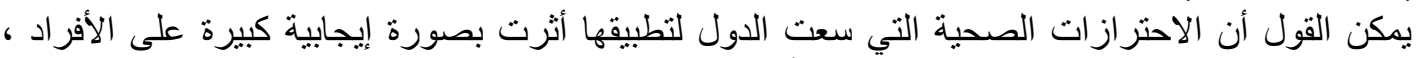

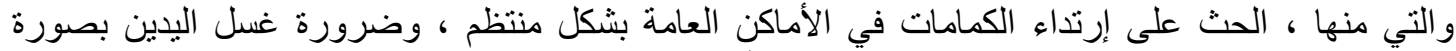

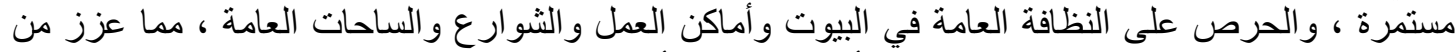

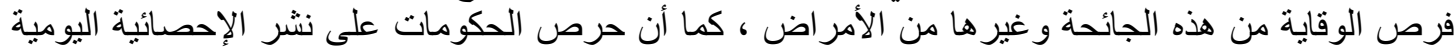

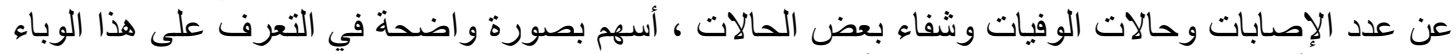

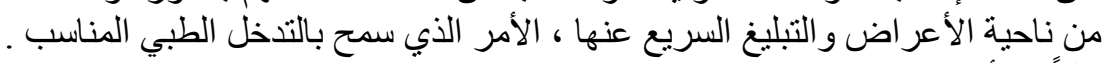

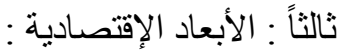

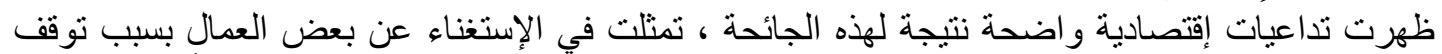

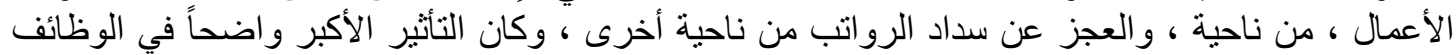

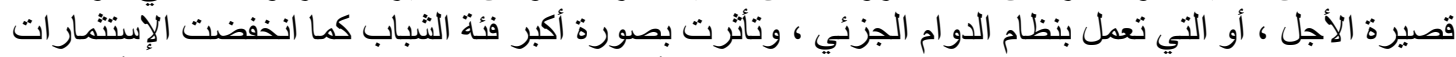

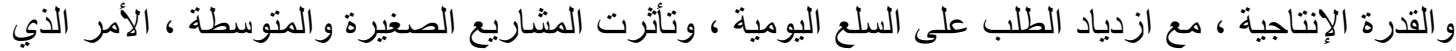

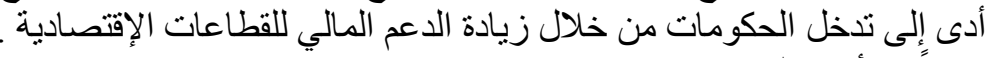

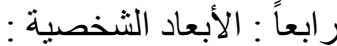

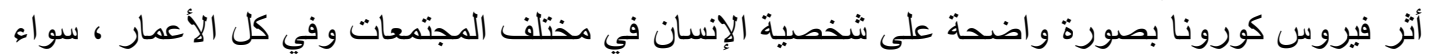

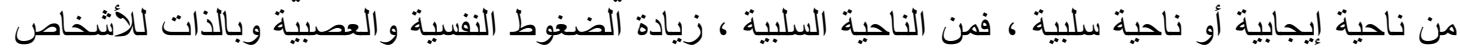

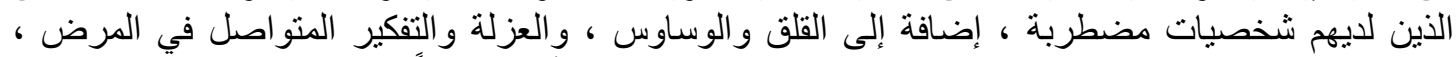

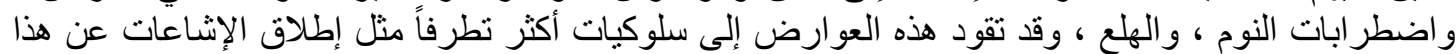

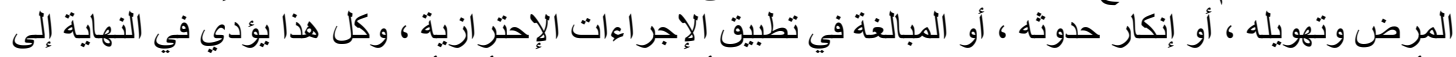

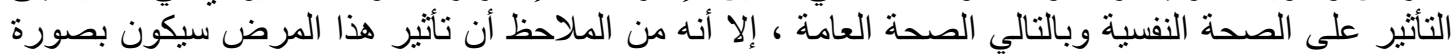

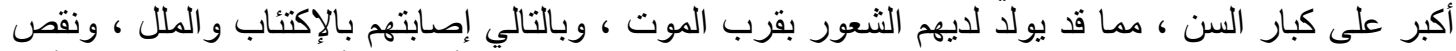

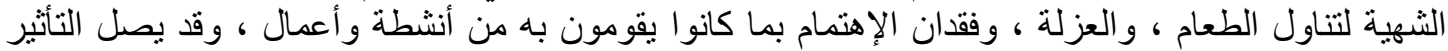

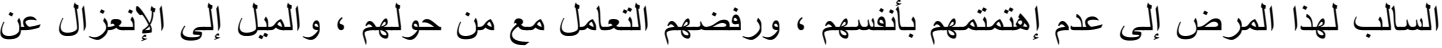

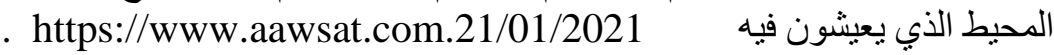




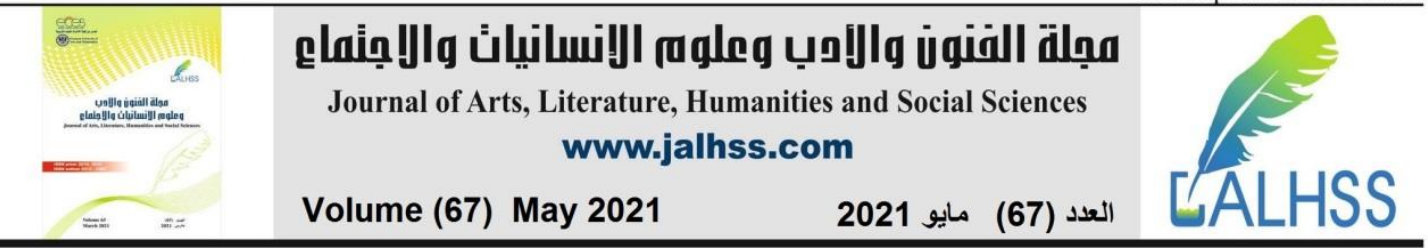

الاراسات السابقة :

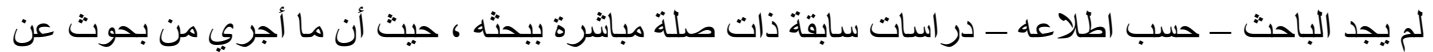

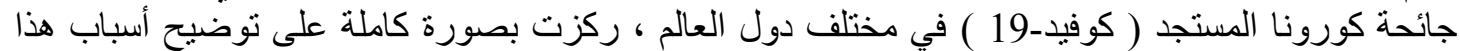

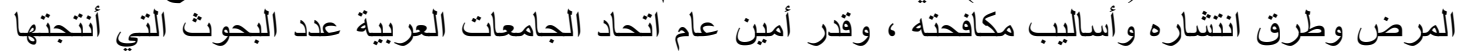

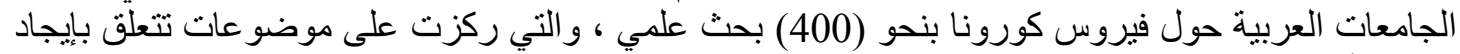

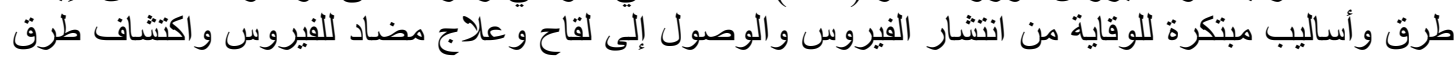

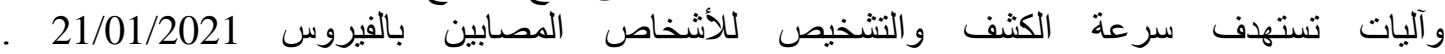
shorouknews.com

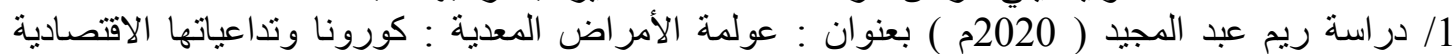

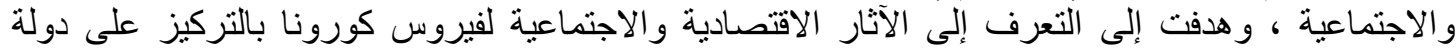

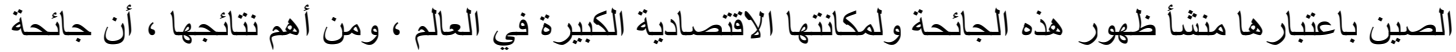

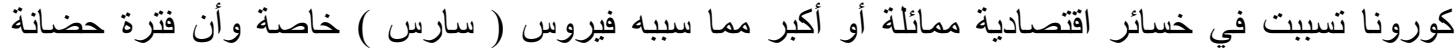

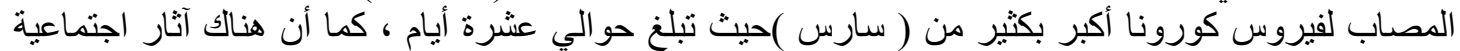

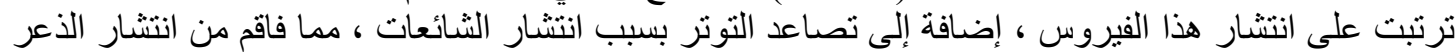
الاجتماعي.

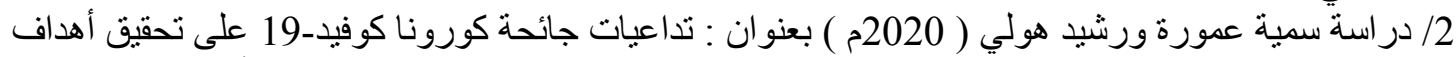

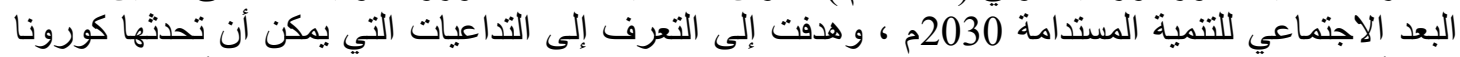

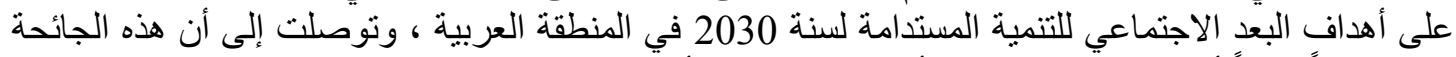

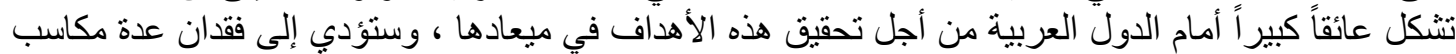

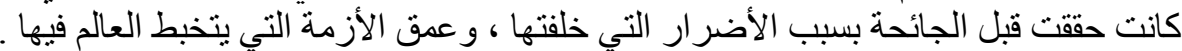

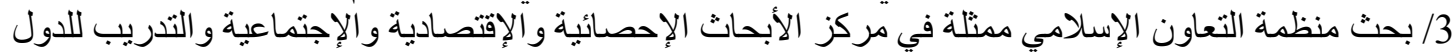
الإسلامية (SESRIC)

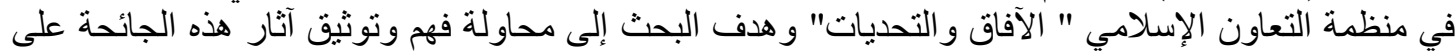

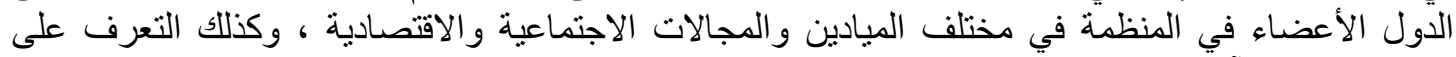

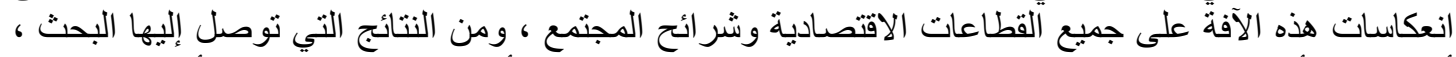

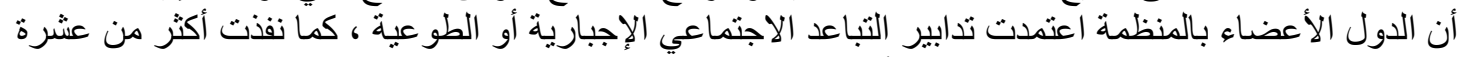

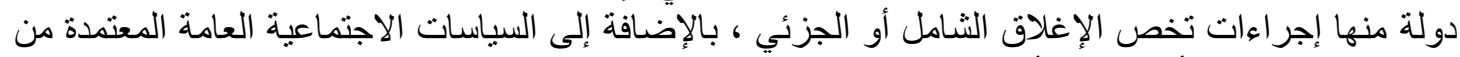

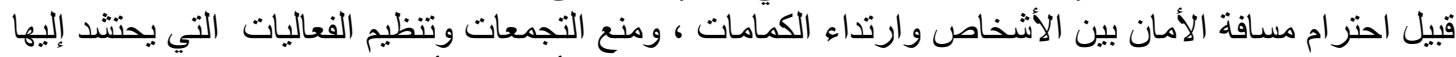

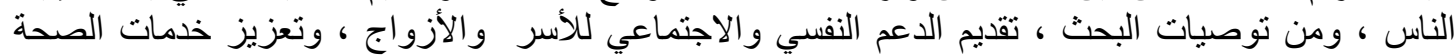

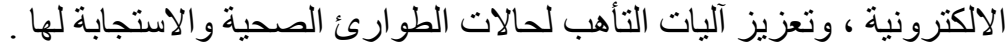

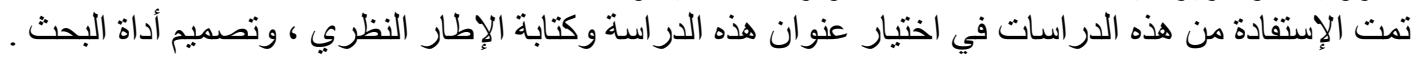

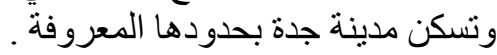

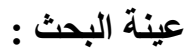
تكونت من (150) أسرة من مدينة جدة ، و اختيرت بطريقة مقصودة ، قلمست إلى الى قسمين لكل قسم (75) أسرة

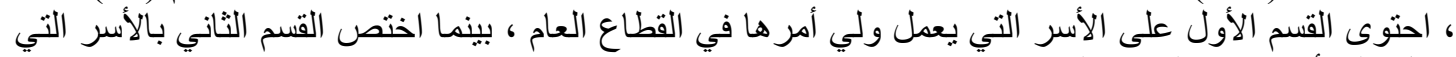

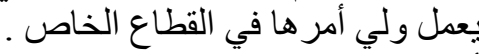
أداة البحث : أبعل

استخدم الباحث الاستبانة أداة للبحث ، حيث تم من خلالها جمع البيانات و المعلومات ، و الاستبانة هي أداة

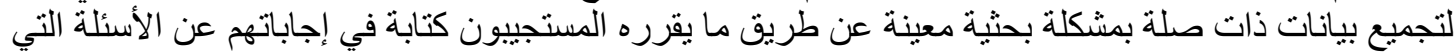
تتضمنها الاستبانة. عطيفة 2012م : 286. 


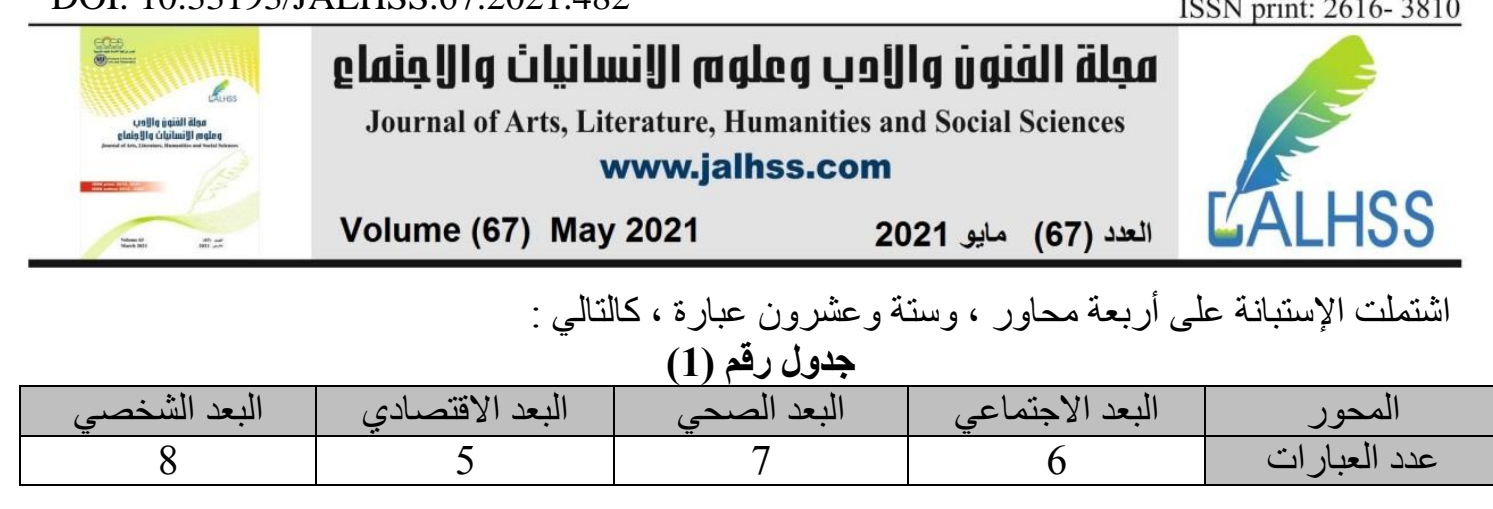

تم اختيار مقياس ليكرت ذو التدرج الخماسي في خيارات الإجابة على كل عبارة من عبارات الاستبانة في

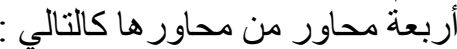
أو افق بشدة : تعني أن العبارة صحيحة ، وارة ، وأن المطلوب نم أداءه بشكل كامل.

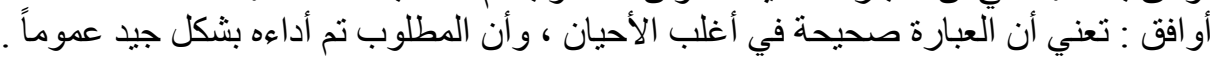

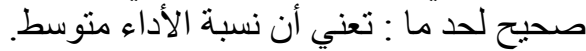

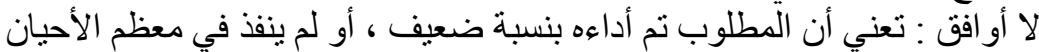

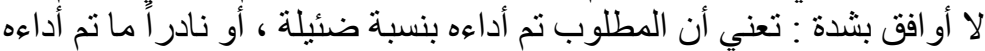

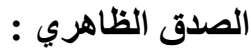

يقصد بالصدق الظاهري أن تقيس الإستبانة ما وضعت لقياسه و ولى من يطبق عليهم من عينة البحث ، حيث الإثي

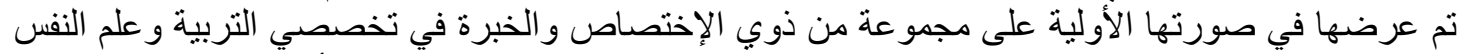

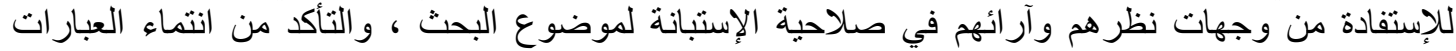

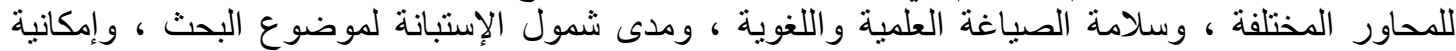

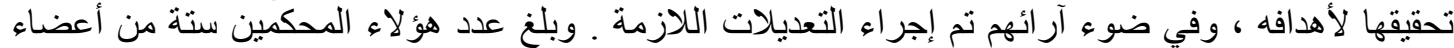

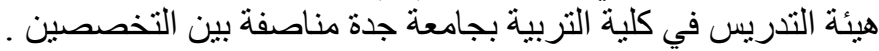

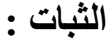

يعني الثبات صلاحية الأداة لقياس المطلوب حسب طبيعة البحث ، وتم حساب الثبات عن طريق التجزئة

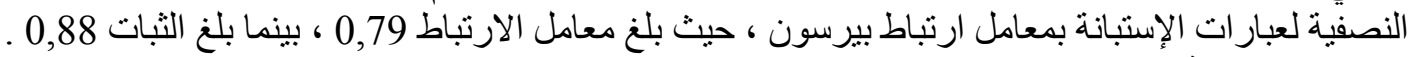

تصحيح الإستبانة : الإنيات الإن تم إعطاء خيار ات الإجابة الدرجات : الإن التالية :

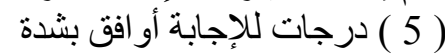

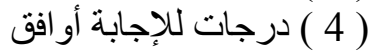

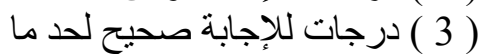

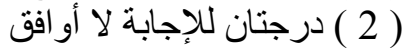

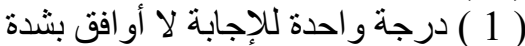
كما تم تحديد مدى مسنوى الدرجات لخيار ات الإجابة على عبار ات الإستبانة كالتالي :

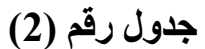

تحديد المستويات

\begin{tabular}{|c|c|c|c|c|c|}
\hline قليلة جدأ & قليلة & متوسطة & كبيرة & كبيرة جدأ & مستوى الدرجات \\
\hline $1.79-1.00$ & $2.59-1.80$ & $3,39-2 \cdot 60$ & $4,10-3,40$ & $5.00-4.20$ & المدى \\
\hline
\end{tabular}

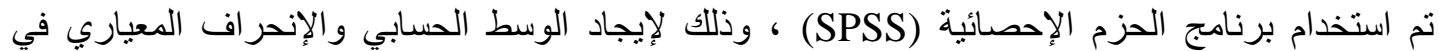

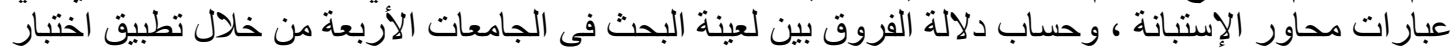

نتائج الار اسة الميدانية السؤال الأول : ما الأبعاد الإجتماعية المرتبطة بالتفاعل الأسري في ظل جائحة كورونا المستجد ( كوفيد-19 ) ؟

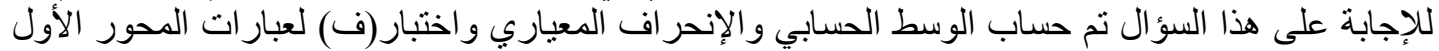

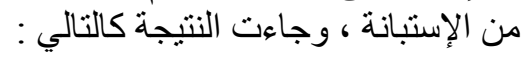




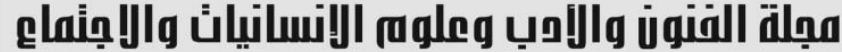

Journal of Arts, Literature, Humanities and Social Sciences www.jalhss.com

\section{Volume (67) May 2021}

العدد (67) مايو 2021

\section{¿ÁLHSS}

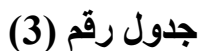

\begin{tabular}{|c|c|c|c|c|c|c|}
\hline 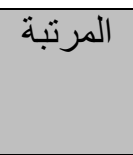 & النتيجة & 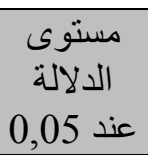 & المعياري - الإنحر اف & الوسط الحسابي & 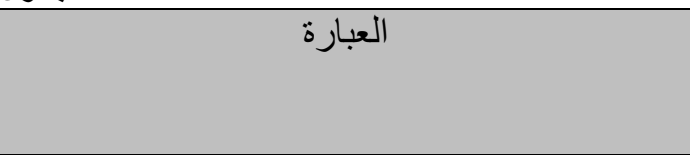 & r \\
\hline 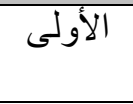 & 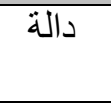 & .01 & .41 & 4,50 & بقائي بالبيت أثر بصورة إيجابية على علاقاتي & 1 \\
\hline 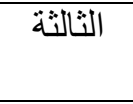 & 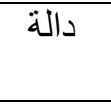 & .02 & .673 & 4,22 & وجودي بالبيت أتاح لي فرصة التعرف أكثر على & 2 \\
\hline 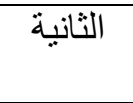 & 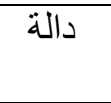 & .03 & .53 & 4,36 & وجودي بالبيت مكنني من اكتشاف سلوكيات جديدة & 3 \\
\hline الأولى & دالة & .01 & .41 & 4,50 & إزداد نو اصلي مع أهلي و أقاربي أثناء وجودي بالبيت & 4 \\
\hline 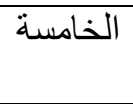 & 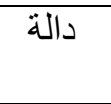 & .60 & .86 & 4,01 & وجودي بالبيت مكنني أكثر من الاهتمام بأموري & 5 \\
\hline الر ابعة & دالة & 02 ،. & 72 ،. & 4,21 & أرشدت أفراد أسرتي بالتعامل بحذر مع الآخرين & 6 \\
\hline
\end{tabular}

يتضح من الجدول رقم (2) أن قيمة المتوسطات تراوحت قيمتها مابين 4,50 - 4,01 ، مما يعني أن أفراد العينة

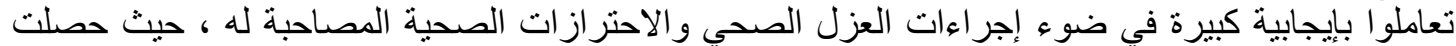

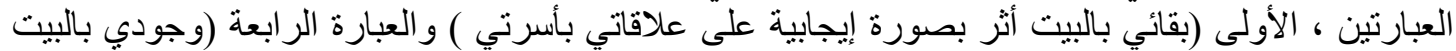

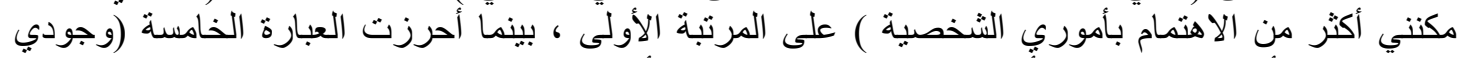

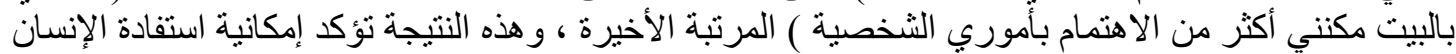

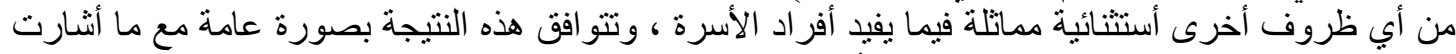

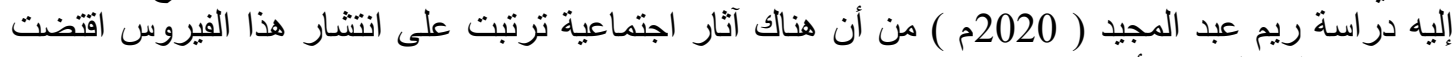

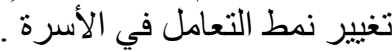

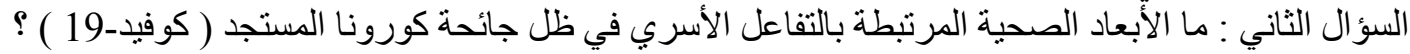

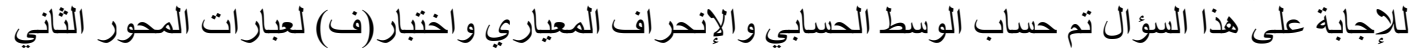

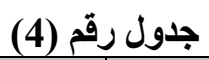

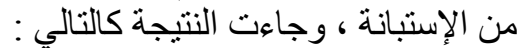

\begin{tabular}{|c|c|c|c|c|c|c|}
\hline المرتبة & النتيجة & مند الدلالة، & الإنحرياري & الوسط الحسابي & 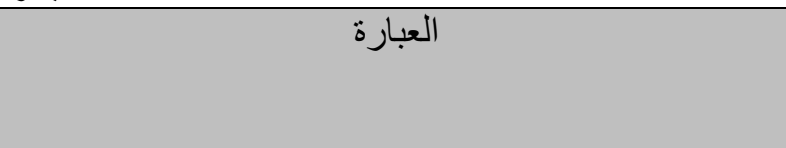 & 5 \\
\hline 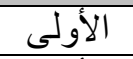 & 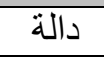 & .01 & .41 & 4,50 & تعرفت على الطريقة الصحيحة لغسل اليدين & 1 \\
\hline الأولى & دالة & .01 & .44 & 4,50 & تعرفت على أهمية النظافة للبيت & 2 \\
\hline الخامسة & 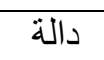 & .04 & .46 & 4,23 & أدركت أكثر أهمية الوقاية من الأمر اض & 3 \\
\hline 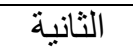 & دالة & .02 & .47 & 4,41 & إزدادت معرفتي بالوقاية من أمر اض كثيرة & 4 \\
\hline 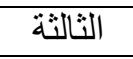 & دالة & 01 & .41 & 4,34 & أدركت أهمية التعامل بإيجابية مع الأمر اض & 5 \\
\hline 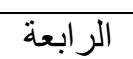 & 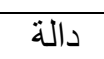 & .03 & .639 & 4,31 & تعرفت أكثر على أهمية تناول الطعام الصحي & 6 \\
\hline السادسة & دالة - الة & .04 & .43 & 4,02 & تعودت على أخذ المعلومات الصحية من مصادر ها المعتمدة & 7 \\
\hline
\end{tabular}

يتضح من الجدول رقم (3) أن قيمة المنوسطات جاءت مابين 4,02 - 4,50 و هي تعني أن أفر اد العينة قد تمكنوا

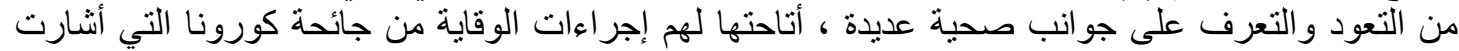

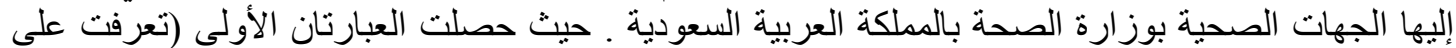

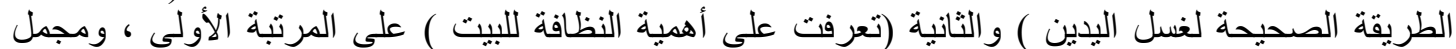

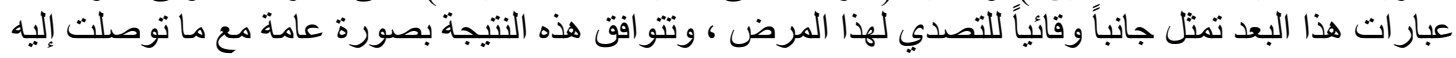




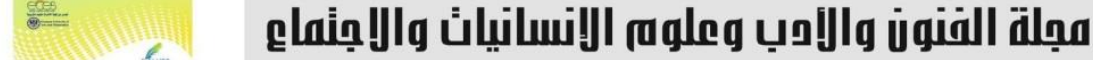

Journal of Arts, Literature, Humanities and Social Sciences www.jalhss.com

\section{Volume (67) May 2021 \\ العدد (67) مايو 2021

در اسة مركز الأبحاث الإحصائية و الاقتصادية و الاجتماعية و التدريب لدول منظمة التعاون الإسلامي ( 2020م )

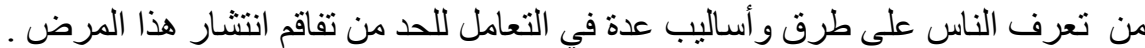

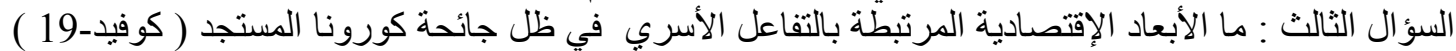
للإجابة على هذا السؤ ال تم حساب الوسط الحسابي و الإنحر اف المعياري واختبار(ف) لعبارات المحور الثالث

\section{جذول (5) (المبط}

\begin{tabular}{|c|c|c|c|c|c|c|}
\hline 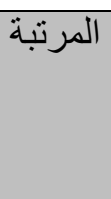 & 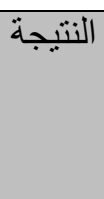 & مستوى الدلالة & الإنحياري & الوسط الحسابي & 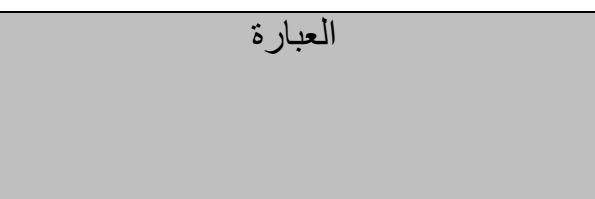 & s \\
\hline 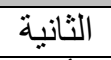 & 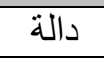 & .603 & .46 & 4,09 & ركزت على شر اء الضروريات فقط & 1 \\
\hline 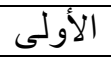 & دالة & .01 & .44 & 4,44 & استطعت تدبير أغر اضي بصورة جيدة & 2 \\
\hline 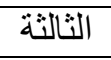 & دالة & .04 & .47 & 4,05 & أدركت أهمية التوفير و الإدخار لأمو الي & 3 \\
\hline 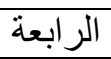 & 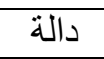 & .02 & .49 & 4,01 & تمكنت من وضع ميز انية شهرية لمصروفاتي & 4 \\
\hline 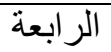 & دالة & .02 & .49 & 4,01 & أقنعت أو لادي بأهمية التوفير و الإدخار & 5 \\
\hline
\end{tabular}

يتضح من الجدول رقم (4) أن قيمة المتوسطات تراوحت بين 4.44 - 4,10 ، مما يعني أن أفراد العينة

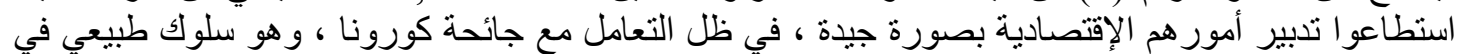

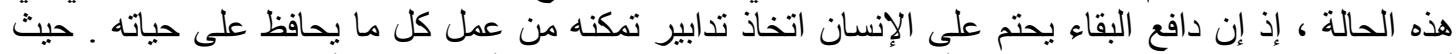

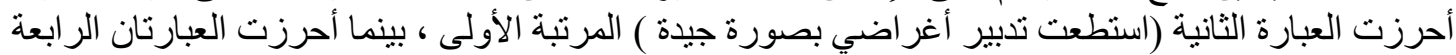

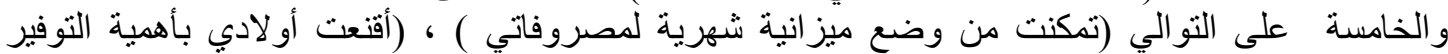

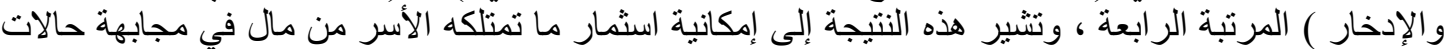

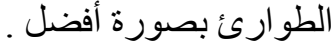

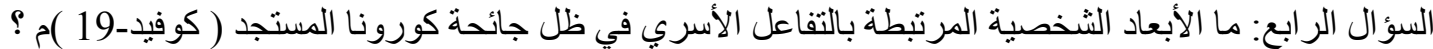

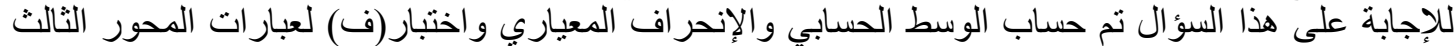

جلول (6) (ل)

\begin{tabular}{|c|c|c|c|c|c|c|}
\hline 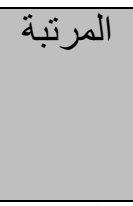 & 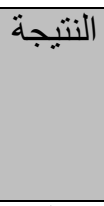 & مستوى الدلالة & 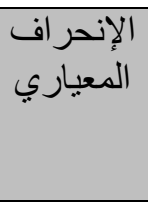 & الوسط الحسابي & 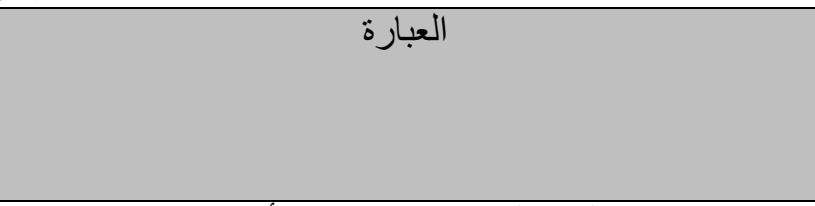 & s \\
\hline 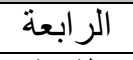 & 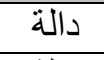 & .03 & .46 & 4,09 & تعلمت الصبر في كثير من أموري & 1 \\
\hline 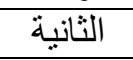 & 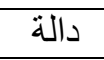 & .03 & .644 & 4,44 & أصبح لدي قدرة جيدة على تحمل الضغوط الحياتية & 2 \\
\hline 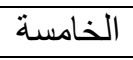 & دالة & .01 & .47 & 4,05 & تمكنت من استغلال قدر اتي الثخصية بصورة أفضل & 3 \\
\hline 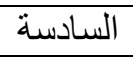 & دالة & .02 & .49 & 4,01 & أدركت فائدة التقيد بالقو انين الرسمية & 4 \\
\hline السادسة & دالة & .01 & .499 & 4,01 & تعلمت مهار ات مفيدة جديدة في حياتي و عملي & 5 \\
\hline 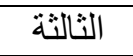 & دالة & .03 & .41 & 4,38 & تمكنت من استثمار أوقات فر اغي فيما يفيدني & 6 \\
\hline الأولى & دالة & .02 & .40 & 4,48 & زادت ثقتي فيما تصدره الجهات الصحية الرسمية من توجيهات & 7 \\
\hline الر ابعة & دالة & .02 & .43 & 4,10 & أرى أنني يمكنني عدم مر اجعة الطبيب إلا للضرورة القصوى & 8 \\
\hline
\end{tabular}




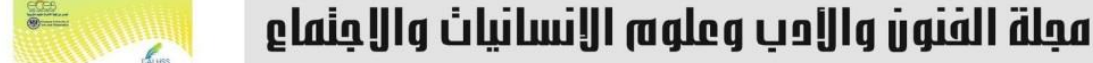 \\ Journal of Arts, Literature, Humanities and Social Sciences www.jalhss.com \\ Volume (67) May 2021 \\ العدد (67) مايو 2021

يتضح من الجدول رقم (5) أن قيمة المتوسطات تراوحت بين 4,01 - 4,48 وهي تمثل درجة استجابة كبيرة من

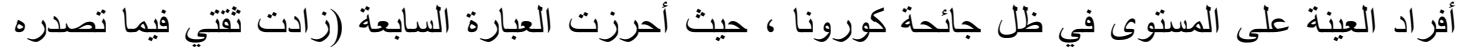

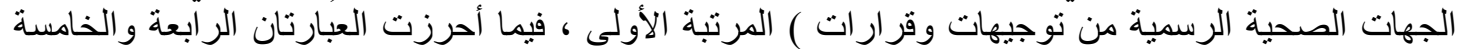

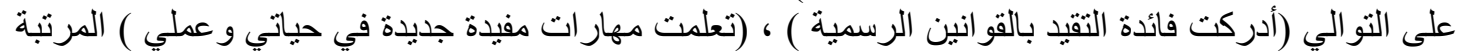

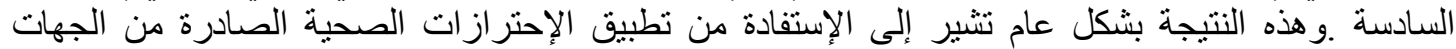

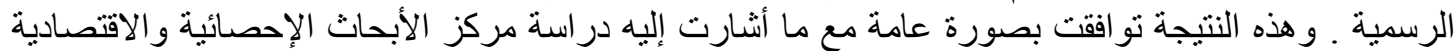

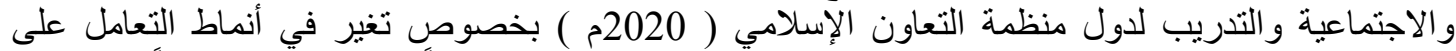

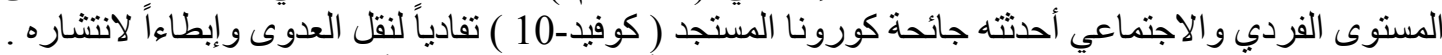

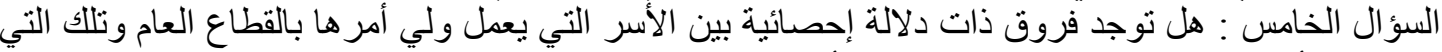

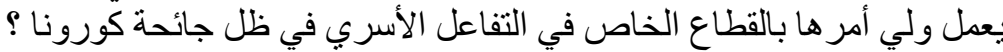
للإجابة على هذا السؤ ال تم حساب المتوسط الحسابي والإنحر اف المعياري واستخدام اختبار (ت) كالتالي :

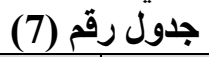

\begin{tabular}{|c|c|c|c|c|c|}
\hline مستوى الدلالة & قالمسة (تبة) & قالجدولية (ت) & اللإنحرياري & الحسابي & البعد \\
\hline دالة د & 1,28 & 0,01 & 0,08 & 3,97 & الاجتماعي \\
\hline دالة د الة & 0,91 & 0,01 & 0,06 & 3.96 & الصحي \\
\hline دالة & 1,12 & 0,02 & 0,04 & 3,92 & الاقتصادي \\
\hline 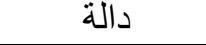 & 1,92 & 0,02 & 0,05 & 3,96 & الشخصي \\
\hline
\end{tabular}

يتضح من الجدول رقم (6) أن قيمة (ت) المحسوبة أكبر من قيمة (ت) الجدولية ، وبالتالي نستنتج أنه لا توجد

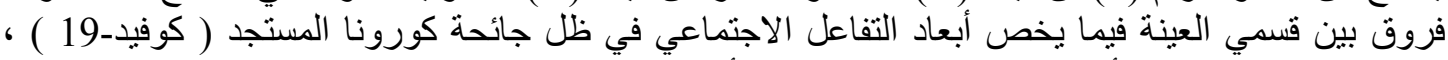

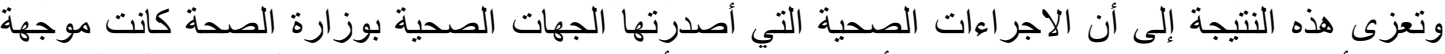

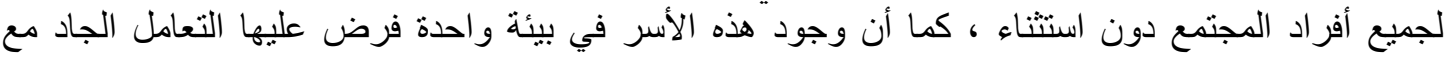

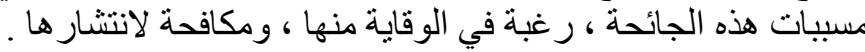

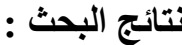

1/ لجائحة كورونا المستجد ( كوفيد-19 ) أثر إيجابي كبير على أبعاد التفاعل الأسري الإجتماعية والصحية

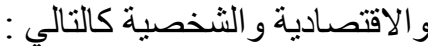
أ. تعزيز العلاقات الأسرية من حيث التعرف التعرف أكثر على أفراد الأسرة ، و اكتشاف مهارات جديدة لديهج ، وزيادة

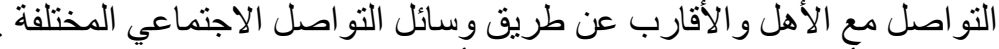

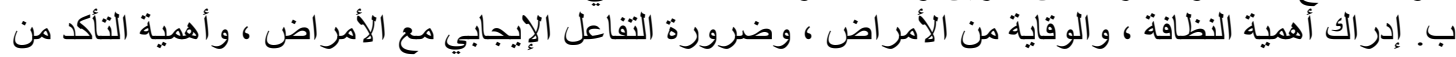

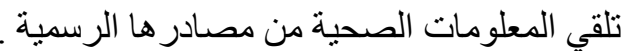

ت. تعلم مهارات اقتصادية جديدة مثل حسن التدبير ، وتعزيز نثافة الإنة الإدخار والتوفير بوضع ميزانية شهرية

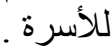

ث. تعلم عادات جديدة على المستوى الثخصي مثل القدرة على التحمل بصورة أفضل ، و واستثمار أوقات الفراغ

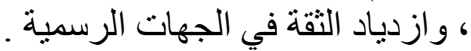

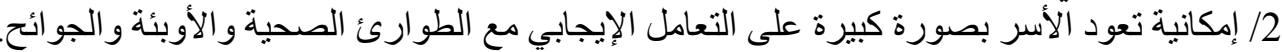
3/ الإستجابة الفورية و الفاعلة من قبل وز ارة الصحة و الجهات الأخرى ذات الصلة في التعامل مع جائحة كورونا

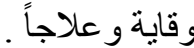
4/ توفر الإمكانيات اللازمة كافة بالمملكة العربية السعودية للتعامل مع أي طوارئ صحية خاصة بالأوبئة و و الأمر اض مستقبلاً.

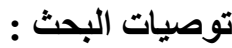

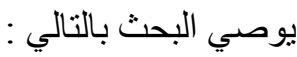

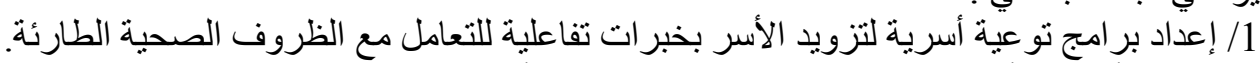

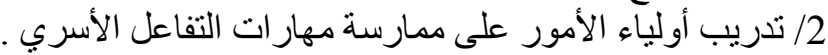




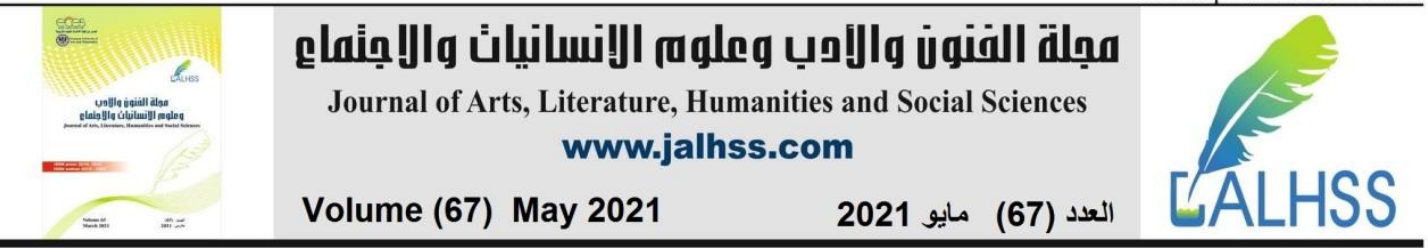

3/ تضمين المقررات الدراسية بمراحل التعليم العام ووالعالي موضوعات دراسية عن التعامل والوقاية مع معائ

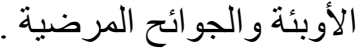
4/ إعداد بر امج تدريبية في مهار ات الحية الحياة بالتركيز على الوقاية من الأمر اض .

1. ابن حبان ، محمد بن أحمد ( 1993م ) ، صحيح ابن حبان ، مؤسسة الرسالة ، بيروت ، ل لبنان.

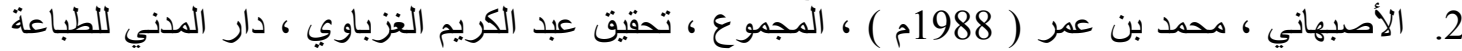

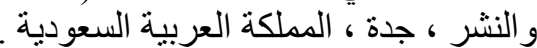

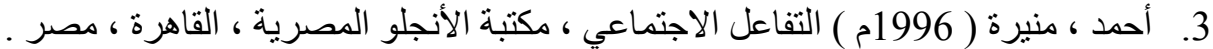

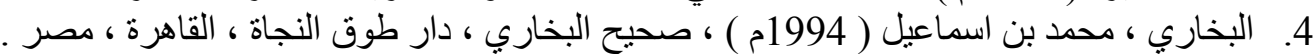

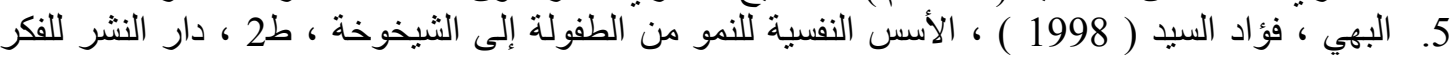

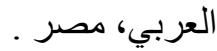

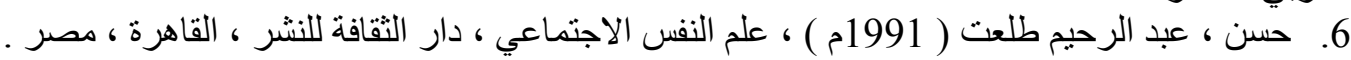

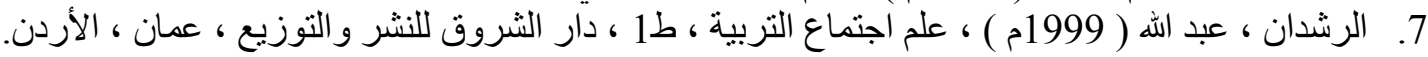

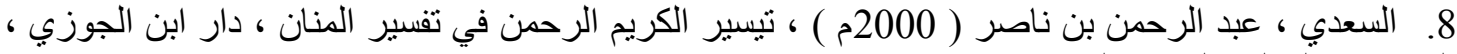

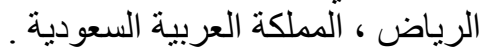
9. الطبر اني ، سليمان بن أحمد ( 2010م ) ، المعجم الأوسط ، دار الحرمين للطباعة والنشر و التوزيع ، القاهرة

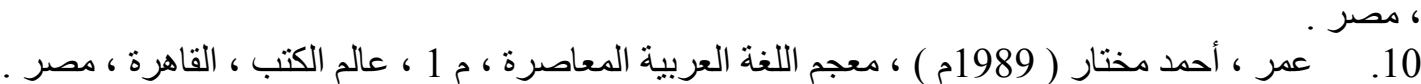$$
\text { 11 }
$$

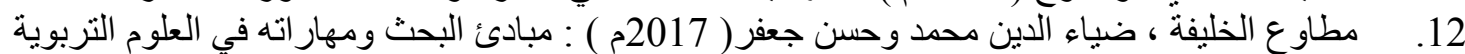

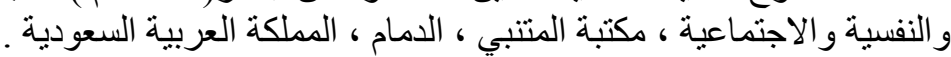

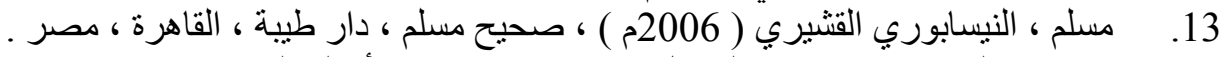

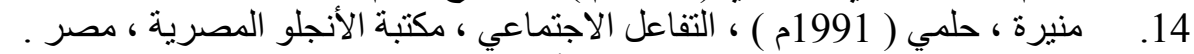

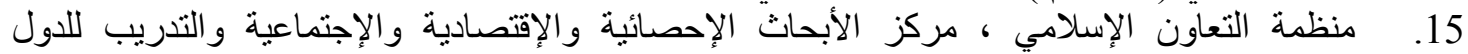
الإسلامية (SESRIC)

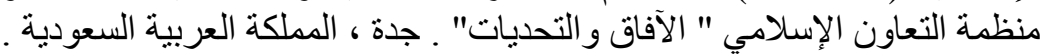

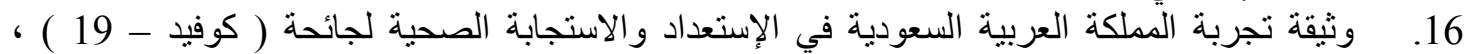
2020 2021 ، وزارة الصحة ، المملكة العربية السعوديةً . salafcenter.org.19/1/2021- .17

18. https://www.mayoclinic.org 19/1/2021 -

19. https://www.aawsat.com 21/01/2021-

20. shorouknews.com 21/01/2021-

\section{References}

1. Ibn Hibban, Muhammad Ibn Ahmad (1993 AD), Sahih Ibn Hibban, The Resala Foundation, Beirut, Lebanon.

2. Al-Asbahani, Muhammad Bin Omar (1988 AD), Al-Majmoo ', edited by AbdulKarim Al-Ghazbawi, Dar Al-Madani for Printing and Publishing, Jeddah, Saudi Arabia.

3. Ahmed, Mounira (1996 AD), social interaction, the Egyptian Angolo Library,

Cairo, Egypt.

4. Al-Bukhari, Muhammad Bin Ismail (1994 AD), Sahih Al-Bukhari, Dar Touq AlNajat, Cairo, Egypt. 


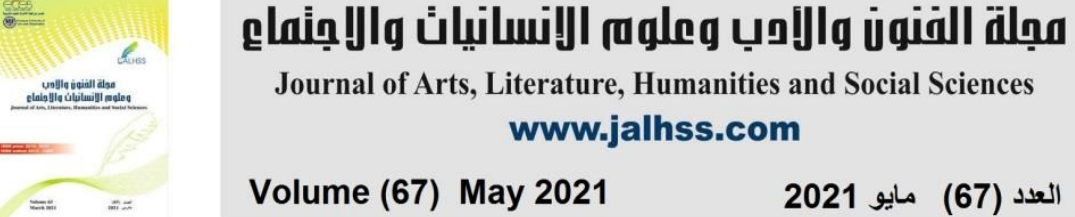

5. Al-Bahi, Fouad El-Sayed (1998), The psychological foundations of growth from childhood to old age, 2nd edition, publishing house of Arab thought, Egypt.

6. Hassan, Abdel-Rahim Talaat (1991 AD), social psychology, Dar Al-Thaqafa publishing house, Cairo, Egypt.

7. Al-Rashdan, Abdullah (1999 AD), Sociology of education, 1st edition, Dar Al Shorouk for publishing and distribution, Amman, Jordan.

8. Al-Saadi, Abd al-Rahman bin Nasser (2000 AD), Tayseer al-Karim al-Rahman . Tafsir al-Manan, Dar Ibn al-Jawzi, Riyadh, Kingdom of Saudi Arabia.

9. Al-Tabarani, Suleiman bin Ahmed (2010 AD), the middle dictionary, Dar AlHaramain for printing, publishing and distribution, Cairo, Egypt.

10. Omar, Ahmed Mukhtar (1989 AD), dictionary of contemporary Arabic Language, Vol. 1, the World of books, Cairo, Egypt.

11. Atifa, Hamdi Abul-Fotouh (1992 AD), Methodology of Scientific Research, Dar Al-Wafaa, Mansoura, Egypt.

12. Mutawa Al-Khalifah, Diaa Al-Din Muhammad and Hassan Jaafar (2017 AD): Research principles and skills in educational, psychological and social sciences, AlMutanabi Library, Dammam, Kingdom of Saudi Arabia.

13. Muslim, Al-Nisaburi Al-Qushayri (2006 AD), Sahih Muslim, Dar Taibah, Cairo, Egypt.

14. Munira, Helmy (1991 AD), Social Interaction, the Anglo Library, Egypt.

15. Organization of Islamic Cooperation, Statistical, Economic and Social Research and Training Center for Islamic Countries (SESRIC) 2020, Social and Economic Impacts of the Covid-19 Pandemic in the OIC Member

16. Countries, "Prospects and Challenges". Jeddah-Saudi Arabia .

17. salafcenter.org.19/1/2021

18. https://www.mayoclinic.org 19/1/2021

19. https://www.aawsat.com $21 / 01 / 2021$

20. shorouknews.com $21 / 01 / 2021$ 